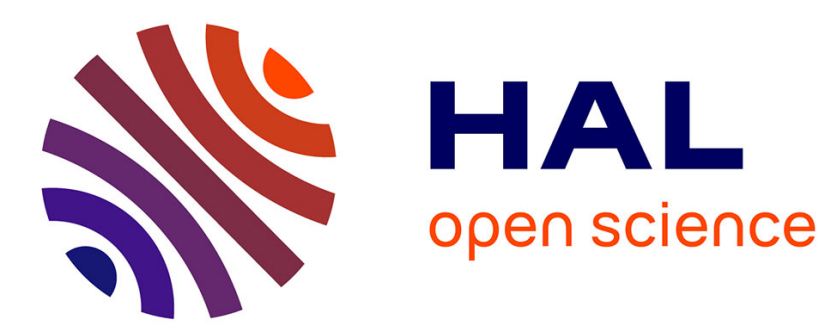

\title{
Investment-Saving Comovement and Capital Mobility: Evidence from Century Long U.S. Time Series Daniel Levy
}

\section{To cite this version:}

Daniel Levy. Investment-Saving Comovement and Capital Mobility: Evidence from Century Long U.S. Time Series. Review of Economic Dynamics, 2000, 3 (1), pp.100-136. 10.1006/redy.1999.0060 . hal-02385594

\section{HAL Id: hal-02385594 https://hal.science/hal-02385594}

Submitted on 28 Nov 2019

HAL is a multi-disciplinary open access archive for the deposit and dissemination of scientific research documents, whether they are published or not. The documents may come from teaching and research institutions in France or abroad, or from public or private research centers.
L'archive ouverte pluridisciplinaire HAL, est destinée au dépôt et à la diffusion de documents scientifiques de niveau recherche, publiés ou non, émanant des établissements d'enseignement et de recherche français ou étrangers, des laboratoires publics ou privés. 


\title{
Investment-Saving Comovement and Capital Mobility: Evidence from Century Long U.S. Time Series*
}

\author{
Daniel Levy \\ Department of Economics \\ Emory University \\ Atlanta, GA 30322-2240 \\ U.S.A \\ Ph: (404) 727-2941 \\ Fax: (404) 727-4639 \\ Email: ECONDL@EMORY.EDU
}

Last Revision: January 8, 1999 


\title{
Investment-Saving Comovement and Capital Mobility: Evidence from Century Long U.S. Time Series
}

\begin{abstract}
This paper makes three contributions: First, I construct annual time series of gross domestic investment and national saving in the U.S. for the 1897-1949 period using historical component series. I compare the qualitative and quantitative properties of the newly constructed series with the properties of four existing alternative series constructed by the Bureau of Economic Analysis, Commerce Department, Kuznets, and Kendrick. Second, I combine the newly constructed data with the Bureau of Economic Analysis' $1929-89$ period data, and the resulting time series are used to re-examine and document the long-run bivariate relationship between the time series of investment and saving. Third, I also examine the short-run as well as the cyclical relationships between the time series of investment and saving. The results reported in this paper indicate that there is a strong long-run and cyclical relationship between investment and saving, and this relationship seems to be independent of the time period considered. Furthermore, I find that during the postwar period the investment-saving comovement is strong and significant also in the short run. However, this is not true during the prewar period. Quantitatively, I find that the investmentsaving relationship is stronger during the postwar period than the prewar period. Feldstein and his coauthors have argued that the high investment-saving correlation reflects imperfect capital mobility. This view, however, is hard to reconcile with the finding that the correlation increased during a period in which it is largely believed that capital markets have become more open and integrated. I conclude, therefore, that long-term capital mobility tests based on investment-saving correlation analysis are not likely to provide an accurate measure of capital mobility.
\end{abstract}

Journal of Economic Literature Classification Numbers: F21, F32, F41, E21, E22

\footnotetext{
* I thank the editor Thomas Cooley, an associate editor, and two anonymous referees for helpful comments and suggestions. The paper is an extension of the manuscript titled "Investment-Saving Comovement, Capital Mobility, and Fiscal Policy," which was presented at the NBER Universities Research Conference on the Macroeconomic Effects of Fiscal Policy. I thank the participants of that conference including Andrew Abel, V.V. Chari, the late Robert Eisner, Robert E. Lucas, Jr., Assaf Razin, and especially the discussants of my paper, Marianne Baxter and Maurice Obstfeld for valuable comments. I also thank the late Martin J. Bailey, Shomu Banerjee, Tamim Bayoumi, Mark Bergen, Rondo Cameron, Robert Chirinko, Betty Daniel, Robert Dekle, Hashem Dezhbakhsh, Clive Granger, Jinook Jeong, Jack Johnston, David Lilien, Giovanna Mossetti, and several university seminar participants for useful comments and suggestions. Finally, I thank Zhongmin Chen and Yongley Wang for research assistance. This research was supported in part by the University Research Committee of Emory University. All errors are mine.
} 


\section{Introduction}

The finding that national saving and domestic investment are correlated in the long run, also known as the Feldstein-Horioka puzzle, has received a considerable attention in the open economy macroeconomy literature. ${ }^{1}$ This is because Feldstein and Horioka [19], Feldstein [18], and Feldstein and Bacchetta [20] interpret the positive investment-saving correlation as an evidence of a low degree of long-term international capital mobility. Feldstein and his coauthors argue that in an open economy, at least part of domestic investment may be financed by foreign saving and therefore national saving and domestic investment can in principle diverge from each other. Consequently, they conclude, the observed strong positive relationship between investment and saving is likely to be a result of capital immobility.

This interpretation of the investment-saving comovement is very controversial and many studies disagree with it because it is in contrast with the general deregulation of capital markets and increased integration of world financial markets that took place over the last 20-30 years. These studies include Tobin [57], Murphy [44], Obstfeld [45, 46], Frankel and MacArthur [24], Summers [55], Bayoumi [6], Frankel [23], and Baxter and Crucini [5]. ${ }^{2}$ On a theoretical level, several studies demonstrate that the investment-saving comovement may be compatible with high degree of capital mobility. ${ }^{3}$ Perhaps more importantly, empirical studies that measure capital mobility directly using various purchasing power parity, interest rate differential, and other conditions, conclude that long term international capital mobility is high and that it has been increasing over time, especially during the last 20-25 years. $^{4}$

Knowing the degree of capital mobility is important for several reasons. First, the finding that variations in saving are associated with variations in investment, if true, implies that a reduction in the U.S. budget deficit will not improve external balance, rather it will increase investment. Second, the effects of monetary policy on investment and external balance, as formulated in the framework of the standard Mundell-Fleming model, depend crucially on the degree of capital mobility. Third, economy's access to open capital markets can reduce the cost of adjustment to negative exogenous shocks (e.g., natural disasters). Further, whether a tax policy that is designed to affect investment (saving) without directly affecting saving (investment), will improve or worsen the economy's international competitiveness depends on the degree of capital mobility. For example, if capital is 
perfectly mobile, then investment taxes will be completely born by labor. Also, the assumption of perfect capital mobility is often employed in standard textbook macroeconomic and financial formulations. A capital immobility would question the validity of this common practice.

This paper makes three contributions. First, I construct time series of gross private domestic investment and national saving for the period 1897-1928 using Goldsmith's [26] historical component series. Second, I combine these data with the Bureau of Economic Analysis' (BEA) 1929-89 investment-saving series yielding a data set covering almost an entire century, which I use to reexamine the long-run investment-saving relationship. Third, I also examine the cyclical and the short-run relationships between the time series of investment and saving. The advantage of using such a long period data is that the degree of international capital mobility has been increasing over time. ${ }^{5}$ Therefore, an examination of the investment-saving relationship using prewar and interwar data, when the degree of capital mobility was relatively low, and comparing it to its postwar behavior can be informative about the validity of the interpretation of the investment-saving comovement in terms of the degree of capital mobility.

The empirical analysis I conduct differs from previous studies in several aspects. First, I construct and use new time series data of gross national saving and gross domestic investment. To evaluate the constructed series, I compare their qualitative and quantitative properties with the properties of four existing alternative series constructed by the BEA, Kuznets, Commerce Department, and Kendrick. Second, I examine the long run, the cyclical, and the short run investment-saving relationships. Most of the existing studies of the Feldstein-Horioka puzzle, in contrast, focus almost exclusively on the long run only. Third, this study focuses on the time series relationship between investment and saving covering the 1897-1989 period. In contrast, most of the existing evidence relies on cross-section analysis, where each observation is computed as a country's 5-10 year average. Although several studies examine the relationship between the time series of saving and investment, the data used are usually limited to the postwar period. Fourth, unlike the existing studies, I use the frequency domain framework which enables me to simultaneously examine the long run, the cyclical, and the short run investment-saving relationships. The existing literature uses cross-section approach to avoid the difficulties caused by a possible investment-saving correlation over the business cycle. The use of frequency domain methods enables us to not only separate the long run correlation from the 
cyclical and short run correlations, but also to estimate and quantify the magnitude of each.

The results indicate that there is a strong long run an cyclical relationship between investment and saving regardless of the time period covered. Since capital was not as mobile internationally in the first half of this century as it has been during, say the last 20-30 years, I conclude that long-term capital mobility tests based on investment-saving correlation analysis are not likely to provide an accurate measure of capital mobility. I also find that investment and saving move together not only in the long run but also in the short run. This is the case for the postwar period but not for the prewar period.

In addition, I theoretically derive the implications of the economy's intertemporal budget constraint in terms of the cointegration and frequency domain characteristics of the long run investment-saving comovement. I find that the cointegration and frequency domain characteristics of the US aggregate investment-saving data are consistent with these theoretical predictions.

The paper is organized as follows. In the next section I describe the historical investment-saving data I construct and the method I use in the construction. In section 3, I evaluate the constructed series by examining their statistical properties and by comparing and contrasting them with the statistical properties of the existing historical series. In Section 4, I describe the econometric method and present the empirical findings. The implications of the findings are discussed in Section 5. The paper ends with a summary of the main results and future extensions. In the Appendix I derive the long run cointegration and frequency domain implications of the economy's intertemporal budget constraint.

\section{Data Construction Methodology}

The annual data set used in this study covers the period 1897-1989. The key time series this study are levels and rates (measured as a fraction of real output) of gross private domestic investment and gross national saving. All variables are measured in 1982 dollars and are constructed using the GNP deflator. The time series data of investment, saving, GNP, and GNP-deflator from 1929 onwards are available from official government sources (e.g., from the National Income and Product Account tables of the BEA) and are well-documented. The GNP and GNP-deflator data for the years 1897-1928, and trend-GNP data for the entire 1897-1989 period are taken from Balke and Gordon [3]. The gross private domestic investment and gross national saving data prior to 1929 are not available from a single source in a consistent form. Although there exist well known investment series for the prewar period constructed by Kuznets [35] and Kendrick [34], these studies do not report 
saving data. Therefore, in order to use investment and saving series derived in a consistent form from the same data source, I chose to construct them. Using Balke and Gordon's [4] language, 1929 is the "borderline" year for our data. Borderline year is the year before which the data is not available. Thus, our goal is to estimate the missing data on gross private domestic investment and gross national saving for the preborderline period.

There are two main methods of backcasting, that is, estimating missing back values of macroeconomic time series: components method and indicators method. A component variable is a variable that is an actual element of the variable estimated. For example, the spending of businesses on industrial construction is a component of gross private domestic investment. An indicator variable, in contrast, is a time series variable which is correlated with the time series of investment or saving in the postborderline period. An example of an indicator variable for the time series of investment is the time series of output.

In the component variable approach, we need to obtain the component series of the backcasted variable for the preborderline period and add them up to estimate the backcasted variable. In the indicator variable approach, we estimate a postborderline period regression relationship between the backcasted variable and the indicator variable/s and use the estimated relationship to extrapolate back, that is to backcast the missing variable. While neither method is perfect, Balke and Gordon [4] demonstrate that the component variable method is, in general, preferred to the indicator variable method. This is because under the component variable method, we are backcasting the variable in question using actual values of the component series. In contrast, the indicator variable method approximates the relationship between the backcasted and indicator/s variables using some form of regression equation. Moreover, we have to be certain that this relationship is stable over the entire period in the sense that the estimated postborderline period regression relationship also applies to the preborderline period. The main disadvantage of the component variable method is that the accuracy of the resulting series depends directly on the accuracy of the component series. Therefore, the estimated series may be contaminated by the measurement errors present in the component series. It is, however, possible that, as Goldsmith [26, Vol. I, p. 38] suggests, “... because the final estimates are the result of combining literally hundreds of series, most of which are independent of each other with respect to sources, methods of collection, coverage, and concepts, errors in individual component series are 
likely to offset each other to a substantial extent in the estimates of national saving or the saving of large saver groups." In addition, Balke and Gordon [4] demonstrate that if both methods use the same set of extrapolators, then the effect of the measurement errors will be of the same order of magnitude under both methods. Therefore, given that component variable method uses more direct information in the estimation process, it seems to be the preferred method.

Therefore, in this paper I use the component variable method. Specifically, I construct the historical time series of gross private domestic investment and national saving using various investment and saving component series contained in Goldsmith's [26] monumental three volume study of saving in the U.S. In his study, Goldsmith provides a detailed time series data set on government, corporate, and personal saving and investment along with their component series and corresponding depreciation and depreciation allowance figures. The time series provided by Goldsmith cover the period 1897-1949. Therefore I construct gross private domestic investment and gross national saving data for this period. Since official investment-saving data for the period after 1929 is available from the National Income and Product Account tables of the BEA, I combine my newly constructed data for the period 1897-1928 with the BEA's data for the period 1929-1989. The constructed data for the period 1929-1949 overlaps with the BEA's official data. In the next section, I exploit this overlapping for evaluation of the accuracy of the newly constructed data in comparison to the BEA's and other existing historical data.

Goldsmith [26, Vol. II, p. 199] actually estimates net national saving as well as net national investment for the period 1897-1949. However, he defines net national investment as a sum of private and public investment plus foreign investment, plus various financial transactions which with the BEA's current definitions would not count as investment. In this paper I use gross figures, and I also need private domestic investment, rather than national investment. Therefore, instead of using Goldsmith's net national investment series, I construct the gross private domestic investment series for the period 1897-1949 from its component series provided by Goldsmith taking into account the current definitions.

The specific component series I use in the construction of the gross private domestic investment series are standard and include expenditures on residential structures such as one-family to four-family homes and multifamily homes and expenditures on residential home alterations and additions. The 
component series also include expenditures on various types of nonresidential business structures such as commercial structures and industrial construction and expenditures on various producer durable goods such as on mining development, farm machinery, and tractors. Finally, the gross domestic investment component series also include change in business inventories and change in farm (livestock and crop) inventories.

To construct the time series of gross national saving, I begin with Goldsmith's own net national saving series and adjust the figures for various capital consumption allowances to convert the net figures into gross. These adjustments include depreciation allowances for local, state, and federal government savings. They also include depreciation allowances for producer durable goods held by corporated businesses, unincorporated businesses, etc.

\section{Evaluation of the Newly Constructed Series}

Figure 1 displays the newly constructed gross private domestic investment series along with the official investment series. Similarly, Figure 2 displays the constructed and the official national saving series. Appendix A provides the hard copy of these series. The official gross domestic investment and gross national saving series come from the BEA's National Income and Product Account tables. The constructed series cover the 1897-1949 period while the official series are available from 1929 and on. Thus, during the 1929-1949 period the constructed and official series overlap. Figure 3 provides the plot of the time series of gross domestic investment and gross national saving for the entire 1897-1989 period. Finally, Figure 4 provides the plot of the same series measured in rates as a share of trend GNP. The series plotted on Figures 3 and 4 are the main series used in the empirical analysis reported in this paper. Note that in Figures 3 and 4 the data for the period 1897-1928 consist of the newly constructed series. For the 1829-1989 period the data consist of the BEA's series.

For comparison and evaluation purposes, Figures 5 and 6 display other existing three alternative measures of gross domestic investment series along with the newly constructed series for the 1897-1929 period. This subperiod was chosen based on the overlapping availability of all four series. Figure 5 provides the plots of the four investment series in levels and Figure 6 - in rates, that is, measured as a share of real output. The source of the three alternative series of Kuznets, Commerce, and Kendrick is Kendrick’s [34, pp. 296-297] Table A-IIb, who reports them in nominal terms for the 
period 1889-1953. Kuznets' measure of investment is reported by Kendrick in Table A-IIb under column (3), while the commerce department's measure, which Kendrick defines as Kuznets' measure of investment minus public investment, is reported in in the same table under column (7). What I term here Kendrick's measure, is the sum of commerce department's measure of investment (column (7) in Kendrick's Table A-IIb) plus change in business inventories (column (8) in Kendrick's Table A-IIb). I used the nominal values of these three alternative investment series along with the GNP deflator series of Balke and Gordon [3] to convert them into 1982 dollars. ${ }^{6}$

Based on these figures, several observations can be made. First, the investment and saving time series data indicate much higher volatility in the earlier period of the century in comparison to the later period (Figures 1-4). This is especially true for the investment and saving rates as indicated by the plots on Figure 4. Even if the period from about 1929 to about after the World War II, which includes the great depression, is excluded from consideration because of the highly volatile nature of the macroeconomy at that time, the data still suggest that from 1897 to the beginning of the big recession the investment and saving series were far more volatile than during the post World War II period. ${ }^{7}$ This finding of more frequent and more volatile cyclical fluctuations during the prewar period is consistent with a similar phenomenon documented for many key macroeconomic variables by numerous authors. For example, Romer [51] finds that in the US economy during the prewar and interwar periods there were a wide range of cycles, including many mild cycles and many severe cycles. In the postwar period, in contrast, she finds that most cycles fall in the moderate range. Gordon and Veitch [27, p. 299] report similar findings for gross national product and for its components including aggregate investment (and the components of the aggregate investment itself) as well as for other macroeconomic time series they study, emphasizing "the enormous decline in the variance of all components in the postwar period." See, for example, Figures 5.1 and 5.2 in Gordon and Veitch's [27, pp. 296-297] study, where they plot the time series of investment and investment components measured as a share of GNP.

Second, the new series, and especially the time series of gross domestic investment exhibit cyclical turning points that roughly match the cyclical turning points of the BEA's series (Figures 1 and 2). Specifically, the investment data plot in Figure 1 indicates that during the four cycles the data exhibit in the 1929-49 period, which is the period where the newly constructed and the official data 
overlap, the timing of the four troughs and of three of the four peaks in the newly constructed and official data exactly coincide. The time series of gross national saving, unfortunately, does not display such a close similarity in terms of cyclical turning points with the official data. Specifically, Figure 2 indicates that the newly constructed saving data exhibit two local peaks in 1933 and 1945 and two local troughs in 1934 and 1946 which are absent from the official data. In terms of the amplitude of the cyclical upturns and downturns, the plots suggest that the newly constructed series exhibit bigger drop in gross domestic investment in 1932 at the trough of the great depression period. The time series of the newly constructed gross national saving, however, does not indicate such a large gap in 1932, although, as mentioned above, it does display a substantial drop in level in 1934. A possible reason for these differences between the official and newly constructed data is that some of the individual component series used in the construction could contain idiosyncratic fluctuations which show up in the constructed series because of the use of components method.

Third, when compared with the existing alternative series of gross domestic investment, the newly constructed series appear to exhibit cyclical fluctuations that are in phase with the existing series (Figures 5 and 6). ${ }^{8}$ These cycles, however, seem to be characterized by higher amplitude and a wider range of variability in comparison to the existing alternative series. To quantify the differences in the volatility properties of the alternative investment series, I have computed two measures of volatility for all investment series reported in this study. First measure is the standard deviation of the series. The second measure is the standard deviation of the (logarithmic) percentage change of the series. These volatility measures were computed for both, investment levels as well as investment rates. The resulting figures are reported in Table 1. As the figures in Table 1 indicate, the newly constructed series indeed exhibit higher volatility in comparison to the existing three series for three of the four volatility measures used. Kendrick's series seem to exhibit second highest volatility followed by Commerce and Kuznets' series with the exception of the first measure where Kuznets' series ranks second highest. Thus, overall, the other three series exhibit less volatility than the newly constructed series. A possible reason for this is the fact that the existing alternative series rely heavily on segmented linear interpolation of missing observations and series, and it has been shown by Dezhbakhsh and Levy [11] that segmented linear interpolation of a time series will yield a new time series which has a lower variance than the original series. 
Fourth, the investment and saving data when measured in rates exhibit a mild downward trend during the beginning of the century. This behavior, however, is not unique to the newly constructed series. Visual examination of Figure 6 reveals that all three alternative gross domestic investment series used here display similar mild downward trend during the period covered. A possible explanation for this may be the finding of Gordon and Veitch [27] that all four categories of the aggregate investment have declined simultaneously during the 1930s and have not fully recovered until after the World War II. Of particular significance may be the construction boom (both residential and nonresidential) of the 1920s and their consecutive decline during the 1930s, also documented by Gordon and Veitch [27]. Goldsmith [26, pp. 7 and 79] has also noted "a very slow secular decline" in the saving-income ratio during the beginning of the century.

\section{Results of Frequency Domain Analysis}

In a bivariate cross-spectral analysis the usual practice is to compute and plot squared coherence, phase, and gain. The squared coherence is analogous to the square of the correlation coefficient at each frequency and represents the degree to which one series, say $x_{p}$, can be represented as a linear function of the other, say $y_{1}$. The higher the squared coherence is at frequency $\omega$, the more closely related are the series at that frequency. Although the coherence will usually vary with the frequency,

the attention is usually focused on frequency bands where the coherence is high. ${ }^{9}$ The phase is a measure of the phase difference or the timing between the frequency components of the two series and is measured in the fraction of a cycle that $x$ leads $y$. The gain indicates how much the spectrum of $y_{1}$ has been amplified to approximate the corresponding frequency component of $x_{i}$. It is essentially the regression coefficient of the process $y_{1}$ on the process $x_{i}$ at frequency $\omega$. A small gain at frequency $\omega$ indicates that $x$ has a little effect on $y$ at that frequency. ${ }^{10}$ In addition to point estimates, I also report their statistical significance. As a significance test for squared coherence, I test whether it equals zero. For phase and gain, I provide $95 \%$ confidence interval. ${ }^{11}$

I use investment and saving time series measured in levels as well as in rates (as a fraction of real GNP). To determine whether the data are stationary or not, I examine the unit root properties of the time series of investment and saving using Augmented Dickey-Fuller $(A D F)$ test. The results are reported in Table 2. The subperiods for which I report unit root tests were selected as follows. The entire data set covers the 1897-1989 period. The second subperiod 1929-89 corresponds to the years 
for which official investment-saving data are available from the BEA. The third subperiod, 1897-1945, is examined since Figures 3 and 4 suggest a change in the trend of the time series of investment and saving at about $1945 .{ }^{12}$

The unit root test results are uniform regardless of how we measure the investment and saving series, in levels or in rates. They indicate nonstationarity of all the series for all samples examined. ${ }^{13}$ The $A D F$ test rejects the null of nonstationarity when the test is applied to the differenced series. Therefore, I conclude that all four series are $I(1)$ which means that the time series of investment and saving can be represented as difference stationary processes. Therefore, all the series were differenced before applying frequency domain analysis. ${ }^{14}$

Next, I estimate the squared coherence, phase, and gain of investment and saving for the 1897-1989 period and its subperiods. ${ }^{15}$ Following the common practice, I present the results in graphical form using Figures 7-9. Regardless of how one measures the time series of investment and saving, in levels or in rates, the spectral analysis results turned out to be almost identical. Therefore, I only present the results using levels. Panel (a) of each figure displays squared coherence, panel (b) displays phase, and panel (c) displays gain.

On these graphs, the frequency $\omega$ is measured in radians, where $0 \leq \omega \leq \pi$. Each frequency corresponds to a particular periodicity according to the mapping, $\xi=\frac{2 \pi}{\omega}$, where $\xi$ denotes the period. For example, with annual data the frequency $\omega=0.524$ corresponds to a period or a cycle of 12 years, while the frequency $\omega=0.78$ corresponds to a cycle of 8 years. On each figure the vertical lines divide the frequency axis into long-run, business cycle, and short-run frequency bands. The cut-off points of these bands are identical to those used in the modern business cycle literature. ${ }^{16}$ For example, according to Englund et al. [17], Kydland and Prescott [36], and Hassler et al. [30], most students of business cycles and growth define business cycles as cycles with 12-32 quarters length. Their estimate of the average length of business cycle is about 20 quarters, which corresponds to the frequency $\omega=$ 1.26 when annual data are used. The frequencies below business cycle frequency band correspond to the long-run, while the frequencies above business cycle frequency band correspond to the shortrun. ${ }^{17}$ Thus, with annual data, the frequencies below 0.78 , i.e., cycles longer than 8 years, correspond to long run, the frequencies $0.78<\omega \leq 2.09$, i.e., $3-8$ year long cycles, correspond to business cycles, and the frequencies higher than 2.09, i.e., cycles of 3 years or shorter, correspond to 
short run. ${ }^{18}$

The estimated squared coherence of investment and saving indicates that for the entire sample period, 1897-1989 (Figure 7a), as well as for the 1897-1945 subperiod (Figure 9a), investment and saving are highly correlated at the frequencies corresponding to the long-run and the business cycle. The point estimates of squared coherence in the long run frequency band are never below 0.85 and average about 0.92 in each case. During the postwar period (Figure 8a), the estimated long run frequency coherence figures are even higher averaging 0.98 . The point estimates of squared coherence in the business cycle frequency band are slightly lower averaging about 0.80 in each case. The horizontal dotted line on these figures is the $95 \%$ critical value for testing the hypothesis, $\mathrm{H}_{0}: \mathrm{K}_{y, x}^{2}(\omega)=0$, where $\mathrm{K}_{y, x}^{2}(\omega)$ denotes the squared coherence. Thus, any coherence value above the dotted line is statistically significant. As Figure 7a shows, the squared coherence is not statistically significant at the frequency bands $2.20 \leq \omega \leq \pi$, when the sample period includes the prewar years. These frequencies correspond to 2-3 year cycles, which is considered short run. However, as Figure 8a indicates, during the 1929-89 subperiod (which excludes the prewar years), investment and saving are correlated at all frequencies, including the short-run frequency band. Here the point estimates of squared coherence in the short run frequency band are never below 0.65 and average about 0.82 . Thus, there is a significant long-run, cyclical, as well as short-run correlation between the time series of investment and saving during the 1929-1989 period. During the 1897-45 period (Figure 9a), I find that there is a significant correlation between investment and saving over the long-run and cyclical frequencies but not over the short-run frequencies.

Figures $7 \mathrm{~b}, 8 \mathrm{~b}$, and $9 \mathrm{~b}$ provide the phase of investment and saving along with $95 \%$ confidence interval. Note that the confidence interval of phase is smaller the higher the squared coherence. This is because the higher the coherence, the lower is the variance of the estimated phase and therefore the more accurate is the phase's estimate. The phase diagrams show that the phase of investment with saving is stable and fluctuates around zero at both, the long-run as well as business cycle frequencies. This is an indicator of a stable contemporaneous relationship between investment and saving. That is, investment and saving are in phase in the long-run as well as over the business cycle. For the 1929-89 subperiod, this is also true in the short-run. ${ }^{19}$

The gain of investment and saving is plotted in Figures 7c, 8c, and 9c along with 95\% 
confidence interval. The plots indicate that when the sample includes the pre-1929 period data (Figures $7 \mathrm{c}$ and $9 \mathrm{c})$, the point estimate of gain starts at about 1.30-1.50 in the neighborhood of the zero frequency, and drops slowly as the time horizon shortens, reaching the $0.25-0.75$ range at the bottom of the business cycle frequency band. At the short-run frequency band, the gain is not statistically different from zero as its confidence interval contains zero. ${ }^{20}$ Thus, there is no statistically significant short-run relationship between investment and saving during the 1897-1928 period. For the 1929-89 sample (Figure 8c), the point estimate of gain is about 1.25 and remains stable in the long-run and business cycle frequency bands. While it drops slightly in the short-run, the point estimate still remains around one and, judging from the confidence interval, statistically it is not different from one. ${ }^{21}$

In sum, cross-spectral analysis of the investment and saving data indicates that there is a statistically significant relationship between investment and saving in the long-run during all sample periods analysed. For the 1929-89 period this relationship is strong also in the business cycle and short-run frequency bands. If the data set contains the 1897-1928 period, however, then at the business cycle frequency band the investment-saving comovement is significantly weaker, and the short-run investment-saving relationship is not even statistically significant. The results also indicate that during the 1897-1928 period the magnitude of the effect of saving on investment is larger in the long-run than over the business cycle. The gain at the long-run frequency band is higher during the prewar period in comparison to the interwar period. ${ }^{22}$

\section{Implications of the Findings}

As discussed in the introduction, Feldstein and his coauthors express the view that the long-run investment-saving comovement is an indicator of a low degree of long-term international capital mobility. If this is true, then the findings reported in this paper would suggest that the long term capital mobility was very low during the various sample periods examined here. This is because, regardless of the sample period considered, one statistically significant empirical regularity we find is the strong long-run investment-saving correlation.

However, as Baxter and Crucini [5] note, most economists disagree with this interpretation. Feldstein's argument is difficult to defend for several reasons. First, the restrictions imposed on the international capital mobility has been declining over time in the world economy. Second, the increased deregulation and integration of the world financial markets' is not compatible with the idea of declining 
capital mobility. And third, studies that measure the postwar international capital mobility directly using various purchasing power parity, interest rate differential, and other equilibrium conditions, conclude that the long term capital is very mobile and that it has been increasing over time. These studies include Sachs [52], Obstfeld [45, 46], Frankel and MacArthur [24], Baxter and Crucini [5], Hutchison and Singh [31], and Popper [48]. For example, Hutchison and Singh [31] examine real interest rate differential between the U.S. and Japan and conclude that capital mobility is very high. Popper [48] uses interest and currency arbitrage conditions along with financial asset returns and finds that capital is very mobile in the long-run.

One finding reported in this paper that is robust to changes in the sample period and in the frequency of the data used is that investment-saving coherence and gain at and near zero frequency are essentially one. It is shown in the Appendix that if the economy's intertemporal budget constraint is balanced and if the levels of investment and saving are nonstationary, then the zero-frequency coherence and gain of investment and saving will equal one. Further, it is shown that investmentsaving coherence and gain of one at zero frequency is an indicator that the two series are cointegrated. It is important to note that these results are independent of the degree of capital mobility.

The standard intertemporal open economy macroeconomic theory also implies that investment and saving should be cointegrated even if capital is perfectly mobile. A country needs to rely on its current account balance in order to repay its external debt. Therefore, unless a country's intertemporal budget constraint is violated, no investment-saving gap can remain permanent. This means that the long run correlation between investment and saving will be one. In other words, the two series will be cointegrated.

To test whether these theoretical predictions are consistent with the data, I examine whether the time series of gross domestic investment and national saving are cointegrated. For this I use Engle and Granger's [16] test which is particularly suitable to a bivariate case like here. The results reported in Tables 3 and 4 indicate that investment and saving are cointegrated regardless of the sample period covered and regardless of whether the variables are measured in levels (Table 3) or in rates (Table 4). Moreover, as the figures in the tables suggest, the results are not sensitive to the normalization chosen. That is, we find that investment and saving are cointegrated regardless of whether we run a regression of saving on investment or a regression of investment on saving. The adjusted $R^{2^{1}}$ in the estimated 
cointegrating regressions are high indicating low bias in the estimated coefficients. The estimated coefficient of the independent variable is around one, suggesting one-to-one long-run relationship between investment and saving which is consistent with our finding of unit gain of investment and saving at the zero frequency band.

Thus, as demonstrated in the Appendix, the interpretation of the zero frequency relationship between investment and saving in terms of capital mobility is not really possible since at the zero frequency what is being tested really is the solvency of the U.S. economy. Therefore, the finding that the investment-saving coherence and gain at the zero-frequency equals one merely means that the U.S. economy does not violate its intertemporal budget constraint. ${ }^{23}$

Another interesting finding we report here is that the long run frequency correlation between investment and saving is higher than the short run frequency correlation. Vikøren [59] reports similar findings for the Norwegian economy. To interpret these findings, Vikøren uses a version of Sachs' [52] model to illustrate theoretically that long run correlation of investment and saving cannot be used as an indicator of the long run capital mobility because investment and saving in the long run will always be correlated due to intertemporal budget constraint. He shows, however, that the short run correlation may be used as an indicator of the short term capital mobility because the intertemporal budget constraint is not necessarily binding in the short run. In particular, he suggests that investmentsaving correlation that is lower in the short run than in the long run is consistent with the idea of an increased short run capital mobility. ${ }^{24}$ The findings we report here are consistent with this interpretation. These findings also underscore the importance of separating the short and long run correlations when studying the investment-saving comovement for assessing the degree of international capital mobility. ${ }^{25}$

Thus, the interpretation of the long run investment-saving comovement in terms of long run capital mobility may not be valid. A natural question to ask at this point is: If it is not capital immobility, then what is causing the time series of investment and saving in the U.S. to move together in the long run? Although intertemporal budget constraint may be one possible cause, various authors have suggested other plausible explanations for the investment-saving comovement, like big country effect, common cause, simultaneity, and endogenous fiscal policy reaction function, and these explanations are compatible with any degree of capital mobility, including perfect capital mobility. This 
question seems still open.

\section{Conclusion}

In this paper I construct annual time series of gross private domestic investment and national saving in the U.S. for the period 1897-1928 using historical component data, which I combine with the BEA's 1929-89 investment-saving series yielding a data set covering almost the entire century. In order to evaluate the newly constructed series, I compare their qualitative and quantitative properties with the properties of four existing alternative series constructed by BEA, Kuznets, Commerce Department, and Kendrick. I find that (i) the investment and saving time series data indicate much higher volatility in the earlier period of the century in comparison to the later period, (ii) the newly constructed series seem to exhibit cyclical turning points that roughly match the cyclical turning points of the BEA's series, (iii) the newly constructed series appear to exhibit more volatile cyclical fluctuations than the existing series, but these fluctuations appear to be in phase with the existing series, and (iv) the investment and saving data when measured in rates exhibit a mild downward trend during the beginning of the century.

I use the newly constructed series to re-examine and document the changing bivariate relationship between the time series of investment and saving. The statistical analysis is done in frequency domain which enables us to study the investment-saving relationship simultaneously in the long-run, over the business cycle, and in the short-run. The results of cross-spectral analysis of the investment-saving time series indicate that there is a long-run as well as cyclical relationship between investment and saving, and that this relationship seems to be strong regardless of the time period covered. For the postwar period I also find that investment and saving tend to move together in the short run as well. Interestingly, I find that this is not the case for the prewar period.

I have also derived some theoretical cointegration and frequency domain implications of the intertemporal budget constraint in terms of the long run investment-saving comovement and their frequency domain characteristics as captured by the coherence and gain of the investment and saving series. Applying these ideas to the newly constructed data set, I demonstrated empirically that these cointegration and frequency domain features of the US aggregate investment-saving data are consistent with the derived theoretical predictions.

The variation in the extent of the investment-saving comovement over the long run, business 
cycle, and short run frequencies underscores the importance of separating the long run correlation of the time series of investment and saving from the short run and cyclical correlations. Indeed, according to Feldstein [18], Bayoumi [6], and Sinn [54] among others, a cross-section approach has been used in the existing empirical literature of the investment-saving correlation primarily to avoid the measurement difficulties associated with the possible comovement of saving and investment over the business cycle. The use of frequency domain methodology has enabled us to not only separate the long run correlation from the cyclical and short run correlations, but also to estimate and quantify the magnitude of each of these three components.

Overall, I find that investment-saving relationship is stronger during the postwar period than the beginning of the century. Therefore, if we believe that capital has become more mobile over time, as most economists think, then we can conclude that capital mobility tests which are based on investmentsaving correlation analysis are not likely to provide an accurate measure of capital mobility. Feldstein and his coauthors have argued that the high investment-saving correlation reflects imperfect capital mobility. This view, however, is hard to reconcile with the finding that the correlation increased during a period in which it is largely believed that capital markets became more open and integrated. If the saving-investment comovement was a good test of international capital mobility, we would expect the comovement to get weaker, not stronger, over time.

An extension of this study tries to identify the exact reasons for the strong investment-saving relationship in the U.S. time series. Despite the fact that various possible explanations have been proposed in the literature, surprisingly their empirical significance has not been examined thoroughly with the U.S. time series data. Notable exceptions are Frankel [22] who examines the potential problem of simultaneity using instrumental variables technique, Obstfeld $[45,46]$ who examines the idea of common cause, and Bayoumi [6], who examines the possibility of endogenous fiscal policy. My preliminary analysis confirms Frankel's findings that the investment-saving relationship remains unaltered when one uses instrumental variables method. I have also looked at the possibility of common cause, which may be leading to the investment-saving comovement. The preliminary results tend to reject this hypothesis as a main driving mechanism. These questions are still under investigation. 


\section{Appendix: Frequency Domain Implications of the Intertemporal Budget Constraint}

In this appendix I show that if the economy's intertemporal budget constraint is balanced, then the zero-frequency coherence and gain between investment and saving will equal one.

Assume that the time series of domestic investment and national saving are nonstationary. That is, $I_{t} \sim I(1)$, and $S_{t} \sim I(1)$. Thus,

$$
\begin{aligned}
& I_{t}=I_{t-1}+u_{t} \\
& S_{t}=S_{t-1}+v_{t},
\end{aligned}
$$

where $u_{t} \sim I(0)$, and $v_{t} \sim I(0)$

Proposition 1: If $I_{t} \sim I(1), S_{t} \sim I(1)$, and the economy is solvent in the sense that its intertemporal budget constraint is satisfied, then investment and saving will be cointegrated with cointegration vector $[1-1]$. That is, $I_{t}-S_{t}=w_{t}$, where $w_{t} \sim I(0)$.

Proof: See Coakley, Kulasi, and Smith [9].

Proposition 2: If $I_{t} \sim I(1), S_{t} \sim I(1)$, and the economy is solvent in the sense that its intertemporal budget constraint is satisfied, then the zero-frequency coherence and gain between investment and saving will equal one.

Proof: By Proposition 1, investment and saving are cointegrated which means that the two processes have a common stochastic trend. Let

$$
\left[\begin{array}{l}
I_{t} \\
S_{t}
\end{array}\right]=\left[\begin{array}{l}
1 \\
1
\end{array}\right] T_{t}+\left[\begin{array}{l}
i_{t} \\
s_{t}
\end{array}\right],
$$

where $T_{t}$ is the common stochastic trend with the property $(1-L) T_{t}=z_{t}, z_{t} \sim \operatorname{iid}\left(0, \sigma_{\mathrm{z}}^{2}\right), i_{t} \sim I(0)$, and $s_{t} \sim I(0)$. Applying a difference operator to (A3) yields a bivariate stationary process

$$
\left[\begin{array}{l}
(1-L) I_{t} \\
(1-L) S_{t}
\end{array}\right]=\left[\begin{array}{l}
1 \\
1
\end{array}\right] z_{t}+\left[\begin{array}{l}
(1-L) i_{t} \\
(1-L) s_{t}
\end{array}\right]^{1}
$$

with the spectral matrix

$$
\mathbf{f}(\omega)=\left[\begin{array}{cc}
f_{I} & f_{I, \Delta S} \\
f_{S, \Delta I} & f_{S}
\end{array}\right]
$$


where the elements on the diagonal are the spectral density functions of $(1-L) I_{t}$ and $(1-L) S_{t}$, while the off-diagonal elements are the cross spectral density functions between $(1-L) I_{t}$ and $(1-L) S_{t}$.

To compute the spectral and cross spectral density functions, I first compute the autocovariance and cross covariance functions and then apply Fourier transformations to the resulting series.

From (A4), $(1-L) I_{t}=z_{t}+(1-L) i_{t}$, with the autocovariance function

$$
\begin{aligned}
\gamma_{\Delta I}(\tau) & =E\left[\left(z_{t+\tau}+\Delta i_{t+\tau}\right)\left(z_{t}+\Delta i_{t}\right)\right] \\
& =E\left(z_{t+\tau} z_{t}\right)+E\left(\Delta i_{t+\tau} \Delta i_{t}\right)+E\left(z_{t+\tau} \Delta i_{t}\right)+E\left(\Delta i_{t+\tau} z_{t}\right) \\
& =\gamma_{z}(\tau)+\gamma_{\Delta i}(\tau)+\gamma_{z, \Delta i}(\tau)+\gamma_{\Delta i, z}(\tau)
\end{aligned}
$$

Applying Fourier transform to both sides of (A6) yields

$$
\begin{aligned}
\frac{1}{2 \pi} \int_{-\infty}^{\infty} \gamma_{\Delta I}(\tau) e^{-i \tau \omega} d \tau & =\frac{1}{2 \pi} \int_{-\infty}^{\infty} \gamma_{z}(\tau) e^{-i \tau \omega} d \tau+\frac{1}{2 \pi} \int_{-\infty}^{\infty} \gamma_{\Delta i}(\tau) e^{-i \tau \omega} d \tau \\
& +\frac{1}{2 \pi} \int_{-\infty}^{\infty} \gamma_{z, \Delta i}(\tau) e^{-i \tau \omega} d \tau+\frac{1}{2 \pi} \int_{-\infty}^{\infty} \gamma_{\Delta i, z}(\tau) e^{-i \tau \omega} d \tau,
\end{aligned}
$$

which, using the standard definitions of spectral and cross spectral density functions, means that

$$
f_{I}(\omega)=f_{z}(\omega)+f_{i}(\omega)+f_{\Delta_{\Delta}}(\omega)+f_{i Z}(\omega) .
$$

Since $f(\omega)$ in general is a complex-valued function, we can write it in cartesian form as

$$
\begin{aligned}
& f_{z, \Delta i}(\omega)=c_{z, \Delta i}(\omega)-i q_{z, \Delta i}(\omega) \\
& f_{\Delta i_{z}}(\omega)=c_{\Delta i_{Z}}(\omega)-i q_{\Delta i, z}(\omega) .
\end{aligned}
$$

where $c$ denotes the cospectral density function and $q$ denotes the quadrature spectral function. But from a result derived by Priestley [49, p. 668, Eq. 9.1.53], we have

$$
f_{\Delta, z}(\omega)=f_{\Delta, \Delta}(\omega)
$$

where bar denotes complex conjugate. Therefore, using (A9),

$$
\underset{f, \Delta i}{f}(\omega)+f_{i z}(\omega)=f_{d_{\Delta} i}(\omega)+f_{z, \Delta i}(\omega)=2 c_{z, \Delta i}(\omega) .
$$

Hence, (A8) can be rewritten as

$$
f_{I}(\omega)=f_{i}(\omega)+f_{i}(\omega)+2 c_{z, \Delta i}(\omega) .
$$


A similar derivation of $\Phi_{S}(\omega)$ and $t_{I, \Delta S}(\omega)$ yields

$$
\begin{aligned}
& f_{S}(\omega)=z_{z} f(\omega)+f_{s}(\omega)+2 c_{z, \Delta s}(\omega) \\
& f_{I, \Delta S}=z_{s}(\omega)+f_{i, \Delta s}(\omega)+{ }_{z, \Delta s}^{f}(\omega)+{ }_{z, \Delta i}^{f}(\omega) .
\end{aligned}
$$

Since $z_{t}$ is a white noise process, its theoretical spectrum is flat and equals $f(\omega)=\frac{\sigma_{\mathrm{z}}^{2}}{2 \pi}$ for all frequencies $-\pi \leq \omega \leq \pi$. In addition, $\Delta i$ and $\Delta s$ are $I(-1)$, and therefore their zero-frequency spectral density, cross spectral density, and cospectral density functions equal zero. Thus, using (A12)-(A14), the spectral matrix (A5) evaluated at the zero-frequency becomes

$$
\left.\mathbf{f}(\omega)^{1}\right|_{\omega=0}=\left[\begin{array}{cc}
\frac{\sigma_{\mathrm{Z}}^{2}}{2 \pi} & \frac{\sigma_{\mathrm{Z}}^{2}}{2 \pi} \\
\frac{\sigma_{\mathrm{Z}}^{2}}{2 \pi} & \frac{\sigma_{\mathrm{Z}}^{2}}{2 \pi}
\end{array}\right] .
$$

From polar representation of $\mathbf{f}(\omega)$ we have

$$
\begin{aligned}
& \mathrm{K}_{y, x}^{2}(\omega)=\frac{\left|f_{y, x}(\omega)\right|^{2}}{f_{y}(\omega) f_{x}(\omega)}=\frac{c_{y, x}^{2}(\omega)+q_{y, x}^{2}(\omega)}{f_{y}(\omega) f_{x}(\omega)}, \text { and } \\
& \Gamma_{y, x}(\omega)=\frac{\left|f_{y, x}(\omega)\right|}{f_{y}(\omega)}=\frac{\left[c_{y, x}^{2}(\omega)+q_{y, x}^{2}(\omega)\right]^{\frac{1}{2}}}{f_{y}(\omega)},
\end{aligned}
$$

where $\mathrm{K}_{y, x}^{2}(\omega)$ and $\Gamma_{y, x}(\omega)$ denote the squared coherence and the gain of investment and saving, respectively (see Jenkins and Watts [33]). Then, using the matrix (A15) along with the definitions of squared coherence and gain provided in (A16) and (A17), we get that at the zero frequency

$$
\begin{aligned}
& \left.K_{\Delta I, \Delta S}^{2}(\omega)^{1}\right|_{\omega=0}=\frac{\left|\frac{\sigma_{\mathrm{Z}}^{2}}{2 \pi}\right|^{2}}{\frac{\sigma_{\mathrm{Z}}^{2}}{2 \pi} \frac{\sigma_{\mathrm{Z}}^{2}}{2 \pi}}=1, \text { and } \\
& \left.\Gamma_{\Delta I, \Delta S}(\omega)^{1}\right|_{\omega=0}=\frac{\left|\frac{\sigma_{\mathrm{Z}}^{2}}{2 \pi}\right|^{1}}{\frac{\sigma_{\mathrm{Z}}^{2}}{2 \pi}}=1 .
\end{aligned}
$$




\section{Footnotes}

1. See, for example, the findings reported by Feldstein and Horioka [19], Sachs [52], Feldstein [18], Murphy [44], Frankel [22], Obstfeld [45, 46], Dooley at al. [13], Feldstein and Bacchetta [20], Bayoumi [6], Levy [38, 39], and Tesar [56].

2. Dekle [10] is a rare exception in that he reports findings that are more in line with the Feldstein-Horioka interpretation.

3. For example, Baxter and Crucini [5] demonstrate that the investment-saving correlation can arise within a quantitatively restricted equilibrium model with perfect capital mobility. The high investment-saving correlation also characterize the models developed by Obstfeld [45], Engel and Kletzer [14], and Backus et al. [2].

4. See, for example, Sachs [52], Obstfeld [45, 46], Frankel and MacArthur [24], Baxter and Crucini [5], Hutchison and Singh [31], and Popper [48]. It should be emphasized, however, that all these and the other studies cited above, with the exception of Bayoumi [6], focus their attention on the postwar period.

5. Most studies of the investment-saving comovement use the post-1947 data. Although Bayoumi [6] constructs a prewar data set for the period 1880-1913 for seven countries, his data set excludes the U.S. In addition, he examines the prewar investment-saving correlation using crosssection regressions.

6. I could not use the real values of the alternative investment series reported by Kendrick [34] in his Table A-IIa, because Kendrick reports them in 1929 dollars while I need them in 1982 dollars. Since Kendrick's tables only go up to 1953, I could not use Kendrick's individual investment deflators (the ratio of Kendrick's nominal and real values for each series) without knowing the individual series' adjustment factors for converting the individual deflators from the base year of 1929 to the base year of 1982. Therefore, instead of estimating the adjustment factors, I chose to use the GNP deflator figures reported by Balke and Gordon [3] to compute the real values of all series in 1982 dollars. Although their GNP deflator figures are reported using 1972 as the base period, converting them into 1982 base period is straightforward because Balke and Gordon report them for the entire 1875-1983 period.

7. Romer [50] shows that even the series that are traditionally considered stable, have become very volatile during the great depression.

8. Goldsmith [26] evaluates the accuracy of the data he constructs in Chapter 5 of Volume II of his work. 
9. An important property of coherence is its invariance under linear filtering. This means that the degree of linear association between time series as measured by coherence is preserved under linear filtering of the time series.

10. In sum, we may interpret coherence, phase, and gain in terms of the ordinary regression terminology if we imagine running a regression equation of $y$ on $x$ at each frequency. The squared coherence is the frequency domain analogue of the time domain correlation coefficient, $R^{2^{1}}$, and is calculated at each frequency. The regression coefficient is just the gain if there is no time lag between $y$ and $x$. If there is a time lag, the gain can be interpreted as the regression coefficient if the series were lagged just the right amount to eliminate any phase shift, and the phase is the angle by which they would have to be shifted. See Engle [15).

11. The confidence interval statistics I use are provided by Jenkins and Watts [33]. As they show (p. 415-418), covariance between two spectral estimators is of order $1 / T^{2^{1}}$ and so, to a good degree of approximation, smoothed spectral estimators at spacing greater than $1 / \mathrm{T}$ may be regarded as uncorrelated. Therefore, provided that the spectral windows are narrow and do not overlap too much, covariance between smoothed spectral estimators will be very small. For an alternative approach of estimating these cross-spectra statistics see Diebold, Ohanian, and Berkowitz [12] who employ Bonferroni tunnels using bootstrap algorithms.

12. Formal testing of a structural break hypothesis using the Chow test indeed indicates a presence of a structural break in the investment-saving series. The values of the Chow test's $F$ statistic (applied to the $A D F$ unit root test equation) for the time series of $I, S, I / Y$, and $S / Y$ are $2.55,2.80,3.59$, and 2.69 , respectively. All four values are statistically significant at $5 \%$.

13. Ghosh [25] also finds that the time series of investment and saving are $I(1)$ regardless of how they are measured, in levels or in rates. The reader might be puzzled by the finding that the investment and saving series are $I(1)$ in levels as well as in rates at the same time. That is, is it technically possible that two variables, say saving and output, be $I(1)$ and their ratio, saving/output also be $I(1)$ ? Although theoretically investment and saving rates are bounded by zero and one and therefore they cannot be random walk processes literally, Granger and Hallman [28] show that the answer to this question in practice is approximately yes. To see this, start with $S_{t}=S_{t-1}+\varepsilon_{t} \sim I(1)$ and $Y_{t}=Y_{t-1}+\tau_{t} \sim I(1)$ and compute the saving rate, $s_{t}=\frac{S_{t}}{Y_{t}}=\frac{S_{t-1}+\varepsilon_{t}}{Y_{t-1}+\tau_{t}}$, using Taylor expansion assuming that $Y_{t}$ is positive and large. Ignoring $O\left(Y_{t-1}^{-2}\right)^{1}$ terms, this yields 


$$
\begin{aligned}
s_{t} & =\frac{S_{t-1}}{Y_{t-1}}+\frac{\varepsilon_{t}}{Y_{t}}-\frac{\tau_{t} S_{t-1}}{Y_{t-1}^{2}}+O\left(Y_{t-1}^{-3}\right) \\
& =s_{t-1}+\frac{\varepsilon_{t}}{Y_{t}}-\frac{\tau_{t} s_{t-1}}{Y_{t-1}}+O\left(Y_{t-1}^{-3}\right) \\
& =\left(1-m_{t}\right) s_{t-1}+\frac{\varepsilon_{t}}{Y_{t}}-\left(\tau_{t}-m_{t}\right) s_{t-1}+O\left(Y_{t-1}^{-3}\right)
\end{aligned}
$$

where $m_{t}=E\left(\frac{\tau_{t}}{Y_{t-1}}\right)$ and $O\left(Y_{t-1}^{-3}\right)^{1}$ denotes the terms that are at most of order $Y_{t-1}^{-3}{ }^{1}$ in magnitude. Thus, for $m_{t}>0, s_{t}$ is a random walk with slowly changing drift, and if $m_{t}=0$, then $s_{t}$ is approximately a random walk. In either case we will get a time series with a strong persistence properties.

14. Although not necessarily required, the time series are usually differenced prior to application of multivariate spectral analysis in order to make them stationary. This is because, as demonstrated by Jenkins and Watts [33], presence of trends in time series may lead to spurious coherences between the time series. It should be noted that the difference filter has been commonly used in frequency domain literature long before the recent development of the unit root literature since it turns out that spectral representations of the original and the differenced series are related. An additional advantage of difference filter is the fact that it belongs to an important class of symmetric digital filters called nonnegative definite filters. These filters have zero phase shift for all frequencies and therefore passing time series through them does not alter the lead-lag relationship between the time series. See also footnote 9 .

15. Various cross-spectral statistics reported in this study were all computed by first estimating the cross periodograms, which then were smoothed in order to get consistent estimates of the series' cross spectral densities. The smoothing was done by averaging the neighboring periodogram ordinates using a rectangular window as suggested by Phillips and Ouliaris [47] for cointegrated time series. That is,

$$
\hat{f}, x\left(\omega_{k}\right)=\frac{1}{W} \sum_{i=-}^{\left(\frac{W}{2}-1\right)} \hat{P}_{y, x}\left(\omega_{k-i}\right)
$$

where $P_{y, \lambda}$ is the estimated cross periodogram, $W$ is the window width, and $k=1,2, \ldots, r$ is the number of ordinates. The window width and the number of ordinates are as follows: for the 1897-1989 period, $W=9$ and $r=92$; for the 1929-1989 period, $W=7$ and $r=64$; and for the 1897-1945 period, $W=7$ and $r=52$. For automatic bandwidth selection procedure in spectral analysis see Andrews and Monahan [1]. 
16. As shown below, the interpretation of the results do not really depend on the exact location of these cut-off points. They are used here only as reference points. Important point to remember is that long run corresponds to the frequencies located on the left hand side of the frequency axis, while the short run corresponds to the frequencies located on the right hand side of the frequency axis. Business cycle frequencies must then fall in between these two extremes.

17. The shortest identifiable cycle is a two-period cycle and it corresponds to the frequency $\omega=\pi$, also known as the Nyquist frequency.

18. These cut-off points are in line with the cut-off points used in many other economic applications of spectral analysis. See, for example, Granger and Hatanaka [29], Lucas [41], Summers [55], Carpenter and Levy [8], Levy [37], and Levy and Chen [40]. It should be noted, however, that although most students of business cycles seem to have adopted these or very similar cut off points and the corresponding frequency bands, the choice of these specific cut off points may seem somewhat arbitrary. It turns out that a similar difficulty exists in other applications of spectral analysis. For example, according to a recent New York Times' report by Browne [7, p. 13], scientists have recently discovered a way of producing a "hard" $\mathrm{X}$-ray laser, an incredibly intense form of radiation capable of producing three-dimensional holograms of objects as small as molecules. The problem is that scientists seem to disagree on the definition of a radiation as "hard" or "soft" in terms of their wavelength: "Although scientists speak of hard and soft X-rays and ultraviolet rays, the distinction between hard and soft are not well-defined. Radiation that has a wavelength at or greater than $10^{-6}$ centimeters is generally considered ultraviolet, while radiation with a wavelength of $10^{-7}$ centimeters or shorter is considered to be X-rays. But the radiation some physicists designate as soft X-rays is referred to by others as hard ultraviolet."

19. Note that a segment of the phase's confidence interval is not shown on Figures $7 b$ and $9 b$ since at frequencies at which the squared coherence is not statistically significant, the phase's confidence interval is not defined. To see this, note that phase's confidence interval is given by

$$
\hat{\phi}_{y, x}(\omega) \pm \arcsin {\sqrt{\frac{2}{v-2} F_{2, v-2}\left(\frac{1-\hat{K}_{y, x}^{2}(\omega)}{\hat{K}_{y, x}^{2}(\omega)}\right)}}^{1}
$$

where $\mathbb{K}_{y, x}^{2}(\omega)$ and $\phi_{y, x}(\omega)$ are the estimated squared coherence and phase, respectively. Under the null hypothesis $\mathrm{H}_{0}: \mathrm{K} \underset{y, x}{2}(\omega)=0$, the quantity

$$
\frac{(v-2) K_{y, x}^{\prime 2}(\omega)}{2\left(1-K_{y, x}^{2}(\omega)\right)}
$$


follows a $F_{2, v-2}$ distribution. Therefore, the expression under the square root will be greater than one

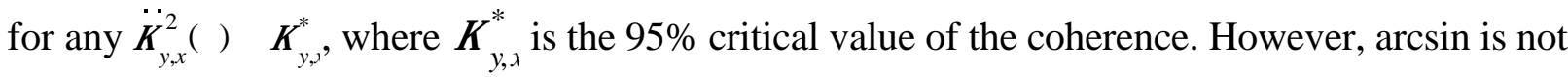
defined if its argument is bigger than 1. Therefore, at frequency bands where the squared coherence is not statistically significant, the confidence interval of phase will be undefined.

20. This is why the bottom part of the confidence interval is not shown in this frequency band.

21. The estimated short-run frequency gain in this subperiod is statistically significant but its variance, as indicated by the range of the confidence interval, is high due to the decrease of the squared coherence in the short-run frequency band. Thus, the confidence interval range of the estimated gain at and around the zero frequency band is slightly above one in all three cases. Economic interpretation of this finding is not obvious. It should be noted, however, that the zero-frequency estimate necessarily relies on a fixed sample and therefore we need to be careful in its interpretation.

22. The results for the prewar period are not directly comparable with Bayoumi's [6] findings since for the 1880-1913 period Bayoumi runs a cross-section time-domain regression, while here I run time-series frequency-domain regressions. However, it is important to note that Bayoumi's findings also indicate that the relationship between saving and investment is weaker during the prewar period in comparison to the postwar period for the set of seven countries (which does not include the U.S.) he considers.

23. Vikøren [59], Coakley, Kulasi, and Smith [9], Jansen [32], Moreno [43], and Levy [39] reach similar conclusions using very different data sets.

24. Feldstein [18, p. 147] discusses various possible reasons for high short-run international capital mobility. His main argument is that "... the short run capital flow is part of a once-for-all adjustment of the international portfolio. When the adjustment is complete, the rate of capital flow returns to a lower level governed by the rate of growth of the world capital stock and the share of international assets in the equilibrium portfolio."

25. I have also examined the dynamic relationship between the postwar investment and saving time series using quarterly US data. The quarterly data covered the period 1947:1-1989:4, and the two subperiods, 1947:1-71:2 and 1971:3-89:4, which correspond to the fixed and flexible exchange rate regimes, respectively. The goal of this sample split was to see whether there are differences in the investment-saving comovement between the fixed and flexible exchange rate periods. Using these data, I estimated the cross-spectra of investment and saving measured in levels as well as in rates. I have also conducted their cointegration analysis. These quarterly results are not reported to save space since they were virtually identical to the annual results reported here. 


\section{References}

1. D. W. K. Andrews and C. Monahan, An improved heteroskedasticity and autocorrelation consistent covariance matrix estimator, Econometrica 60 (1992), 953-966.

2. D. K. Backus, P. J. Kehoe, and F. E. Kydland, International real business cycles, J. Polit. Econ. 100 (1992), 745-775.

3. N. S. Balke and R. J. Gordon, Historical Data, in "The American Business Cycle: Continuity and Change" (R. J. Gordon, Ed.), pp. 781-850, The University of Chicago Press, Chicago, 1986.

4. N. S. Balke and R. J. Gordon, The estimation of prewar gross national product: methodology and new evidence, J. Polit. Econ. 97 (1989), 38-92.

5. M. Baxter, and M. J. Crucini, Explaining saving-investment correlations, Amer. Econom. Rev. (1993), 416-436.

6. T. Bayoumi, Saving-investment correlations: immobile capital, government policy, or endogenous behavior? IMF Staff Papers 37 (1990), 360-387.

7. M. W. Browne, Scientists see hope for harnessing an elusive, intense laser, New York Times, August 25 (1994), Section A, p. 13.

8. R. Carpenter and D. Levy, Seasonal cycles, business cycles, and the comovement of inventory investment and output, J. Money, Credit, Banking 30 (1998), 331-346.

9. J. Coakley, F. Kulasi, and R. Smith, Current account solvency and the Feldstein-Horioka puzzle, Econom. J. 106 (1996), 620-627.

10. R. Dekle, Saving-investment associations and capital mobility: on the evidence from Japanese regional data, J. Internat. Econom. 41 (1996), 53-72.

11. H. Dezhbakhsh and D. Levy, Periodic properties of interpolated time series, Econom. Letters 44 (1994), 221-228.

12. F. X. Diebold, L. E. Ohanian, and J. Berkowitz, "Dynamic equilibrium economies: a framework for comparing models and data," National Bureau of Economic Research, Technical Working Paper No. 174, February (1995).

13. M. Dooley, J. Frankel, and D. J. Mathieson, International capital mobility: what do saving-. investment correlations tell us?" IMF Staff Papers 34 (1987), 503-530.

14. C. M. Engel and K. M. Kletzer, Saving and investment in an open economy with non-traded goods, Internat. Econom. Rev. 4 (1989), 735-52.

15. R. E. Engle, Interpreting spectral analysis in terms of time-domain models, Annals Econom. Soc. Measur. Winter (1976), 89-101.

16. R. E. Engle and C. W. J. Granger, Cointegration and error correction: representation, estimation, and testing, Econometrica 55 (1987), 251-276.

17. P. Englund, T. Persson, and L. E. O. Svensson, "Swedish business cycles: 1861-1988," Seminar Paper No. 473, Institute for International Economic Studies (1990).

18. M. Feldstein, Domestic saving and international capital movement in the long run and the short run, Europ. Econom. Rev. 21 (1983), 129-151.

19. M. Feldstein and C. Horioka, Domestic saving and international capital flows, Econom. J. 90 (1980), 314-29.

20. M. Feldstein and P. Bacchetta, "National saving and international investment," National Bureau 
of Economic Research, Working Paper No. 3164 (1989).

21. G. S. Fishman, "Spectral Methods in Econometrics," Harvard University Press, Cambridge, MA, 1969.

22. J. A. Frankel, International Capital Mobility and Crowding-Out in the U.S. Economy: Imperfect Integration of Financial Markets or of Goods Markets? in "How Open Is the U.S. Economy?" (R. Hafer, Ed.), pp. 33-67, Lexington Books, Lexington, MA, 1986.

23. J. A. Frankel, Quantifying International Capital Mobility in the 1980s, in "National Saving and Economic Performance" (B. D. Bernheim and J. B. Shoven, Eds.), University of Chicago Press, Chicago, 1991.

24. J. A. Frankel and A. T. MacArthur, Political vs. currency premia in international real interest rate differentials, Europ. Econom. Rev. 32 (1988), 1083-1121.

25. A. R. Ghosh, "International Capital Mobility and Optimal Current Account Behavior: An Empirical Investigation,” Discussion Paper No. 50, Princeton University, February 1990.

26. R. W. Goldsmith, “A Study of Saving in the United States, Volumes I, II, and III," Princeton University Press, Princeton, NJ, 1955.

27. R. J. Gordon and J. M. Veitch, Fixed Investment in the American Business Cycle, 1919-1983, in "The American Business Cycle: Continuity and Change" (R. J. Gordon, Ed.), pp. 267-335, The University of Chicago Press, Chicago, 1986.

28. C. W. J. Granger and J. Hallman, "The algebra of I(1)," FEDS Working Paper No. 45, Board of Governors of the Federal Reserve System, 1988.

29. C. W. J. Granger and M. Hatanaka, "Spectral Analysis of Economic Time Series," Princeton University Press, Princeton, NJ, 1964.

30. J. Hassler, P. Lundvik, T. Persson, and P. Söderlind, “The Swedish Business Cycle: Stylized Facts Over 130 Years," Discussion Paper 63, Institute for Empirical Macroeconomics, May 1992.

31. M. M. Hutchison, and N. Singh, "Long-Term International Capital Mobility: New Evidence from Equilibrium Real Interest Rate Linkages,” Working paper No. PB93-06, Federal Reserve Bank of San francisco, April 1993.

32. W. J. Jansen, Estimating saving-investment correlations: evidence for OECD countries based on an error correction model, J. Intern. Money Finance 15 (1996), 749-781.

33. G. M. Jenkins and D. G. Watts, "Spectral Analysis and its Applications," Holden Day, San Francisco, 1968.

34. J. W. Kendrick,"Productivity Trends in the United States," Princeton University Press, Princeton, NJ, 1961.

35. S. Kuznets, "National Product Since 1869," National Bureau of Economic Research, Inc., New York, 1946.

36. F. Kydland and E. C. Prescott, Business cycles: real facts and monetary myth, Quart. Rev., Federal Reserve Bank of Minneapolis (1990), 3-18.

37. D. Levy, Output, capital, and labor in the short, and long run, South. Econom. J. 60 (1994), 946-960.

38. D. Levy, Investment-saving comovement under endogenous fiscal policy, Open Economies Rev. 6 (1995), 237-254. 
39. D. Levy, "Is the Feldstein-Horioka Puzzle Really a Puzzle?” Working Paper, Emory University, 1998.

40. D. Levy and H. Chen, Estimates of quarterly capital stock series for the post war U.S. economy, Rev. Income Wealth 40 (1994), 317-349.

41. R. E. Lucas, Jr., Two illustrations of the quantity theory of money, Amer. Econom. Rev. 70 (1980), 1005-1014.

42. J. MacKinnon, Critical Values for Cointegration Tests, in "Long-Run Economic Relationships: Readings in Cointegration" (R. E. Engle and C. W. J. Granger, Eds.), pp. 267-276, Oxford University Press, New York, 1991.

43. R. Moreno, Saving-investment dynamics and capital mobility in the US and Japan, J. Internat. Money Finance 16 (1997), 837-863.

44. R. G. Murphy, Capital mobility and relationship between saving and interest rates in OECD countries, J. Internat. Money Finance 3 (1984), 327-342.

45. M. Obstfeld, Capital mobility in the world economy: theory and measurement, CarnegieRochester Conf. Series on Pub. Pol. 24 (1986), 55-104.

46. M. Obstfeld, "How Integrated Are World Capital Markets: Some New Tests," National Bureau of Economic Research, Working Paper No. 2075, 1986.

47. P. C. B. Phillips and S. Ouliaris, Testing for cointegration using principal components method, J. Econom. Dynamics Control 12 (1988), 205-230.

48. H. Popper, Long-term covered interest parity: evidence from currency swaps, J. Internat. Money Finance 12 (1993), 439-448.

49. M. B. Priestley, "Spectral Analysis and Time Series," Academic Press, New York, 1981.

50. C. D. Romer, The prewar business cycle reconsidered: new estimates of gross national product, 1869-1908, J. Polit. Econ. 97 (1989), 1-37.

51. C. D. Romer, Remeasuring business cycles, J. Econom. Hist. 54 (1994), 573-609.

52. J. D. Sachs, The current account and macroeconomic adjustment in the 1970's, Brooking. Papers Econom. Activity. 1 (1981), 201-268.

53. W. H. Shaw, "Value of Commodity Output since 1869," National Bureau of Economic Research, Inc., New York, 1947.

54. S. Sinn, Saving-investment correlations and capital mobility: on the evidence from annual data, Econom. J. 102 (1992), 1161-1170.

55. L. H. Summers, The Non-Adjustment of the Interest Rates: A Study of the Fisher Effect, in "Macroeconomics, Prices, and Quantities" (J. Tobin, Ed.), pp. 201-241, The Brookings Institution, Washington, DC, 1983.

56. L. L. Tesar, Saving, investment, and international capital flows, J. Internat. Econom. 31 (1991), 55-78.

57. J. Tobin, Domestic saving and international capital movements in the long run and the short run by M. Feldstein: comment, Europ. Econom. Rev. 21 (1983), 153-156.

58. B. Trehan C. E. Walsh, Common trends, the government's budget constraint, and revenue smoothing, J. Econom. Dynamics Control 12 (1988), 425-444.

59. B. Vikøren, The Saving-Investment Correlation in the Short and in the Long Run, Essay No. 4 in "Interest Rate Differential, Exchange Rate Expectations, and Capital Mobility: Norwegian Evidence” by B. Vikøren, pp. 129-168, Norges Banks Skriftserie, No. 21, Oslo, 1994. 
TABLE I

Volatility Measures of Alternative Gross Domestic Investment Series: U.S., 1897-1929

\begin{tabular}{lcccc}
\hline & Constructed & Kuznets & Commerce & Kendrick \\
\hline Standard Deviation of Levels & 22.470 & 23.490 & 18.310 & 19.650 \\
$\begin{array}{lccc}\text { Standard Deviation of Rates } \\
\text { Standard Deviation of Percentage }\end{array}$ & 0.037 & 0.026 & 0.030 & 0.035 \\
$\begin{array}{l}\text { Change of Levels } \\
\text { Standard Deviation of Percentage }\end{array}$ & 0.298 & 0.111 & 0.130 & 0.247 \\
Change of Rates & & 0.102 & 0.107 & 0.227 \\
\hline
\end{tabular}


TABLE II

Unit Root Tests of Gross Domestic Investment and National Saving: US, 1897-1989

\begin{tabular}{|c|c|c|c|c|c|c|}
\hline \multirow[t]{2}{*}{ Sample Period } & \multirow[t]{2}{*}{ Series } & \multicolumn{2}{|c|}{$A D F$ Statistic $^{a}$} & \multicolumn{3}{|c|}{ Critical Values } \\
\hline & & Levels & $\begin{array}{c}\text { First } \\
\text { Difference }\end{array}$ & $1 \%$ & $5 \%$ & $10 \%$ \\
\hline $\begin{array}{l}1897-1989 \\
(n=93)\end{array}$ & $\begin{array}{l}I \\
S \\
I / Y \\
S / Y\end{array}$ & $\begin{array}{l}-1.67 \\
-1.69 \\
-2.52 \\
-3.04\end{array}$ & $\begin{array}{l}-5.33^{*} \\
-5.57^{*} \\
-6.86^{*} \\
-6.95^{*}\end{array}$ & $\begin{array}{l}-4.06 \\
-4.06 \\
-4.06 \\
-4.06\end{array}$ & $\begin{array}{l}-3.45 \\
-3.45 \\
-3.45 \\
-3.45\end{array}$ & $\begin{array}{l}-3.15 \\
-3.15 \\
-3.15 \\
-3.15\end{array}$ \\
\hline $\begin{array}{l}1929-1989 \\
(n=61)\end{array}$ & $\begin{array}{l}I \\
S \\
I / Y \\
S / Y\end{array}$ & $\begin{array}{l}-2.93 \\
-3.15 \\
-2.50 \\
-2.68\end{array}$ & $\begin{array}{l}-4.07^{* *} \\
-4.04^{* *} \\
-4.19^{*} \\
-3.74^{* *}\end{array}$ & $\begin{array}{l}-4.11 \\
-4.11 \\
-4.11 \\
-4.11\end{array}$ & $\begin{array}{l}-3.48 \\
-3.48 \\
-3.48 \\
-3.48\end{array}$ & $\begin{array}{l}-3.16 \\
-3.16 \\
-3.16 \\
-3.16\end{array}$ \\
\hline $\begin{array}{l}1897-1945 \\
(n=48)\end{array}$ & $\begin{array}{l}I \\
S \\
I / Y \\
S / Y\end{array}$ & $\begin{array}{l}-2.54 \\
-2.73 \\
-3.16 \\
-3.17\end{array}$ & $\begin{array}{l}-5.18^{*} \\
-5.29 * \\
-5.42^{*} \\
-5.25^{*}\end{array}$ & $\begin{array}{l}-4.15 \\
-4.15 \\
-4.15 \\
-4.15\end{array}$ & $\begin{array}{l}-3.50 \\
-3.50 \\
-3.50 \\
-3.50\end{array}$ & $\begin{array}{l}-3.18 \\
-3.18 \\
-3.18 \\
-3.18\end{array}$ \\
\hline
\end{tabular}

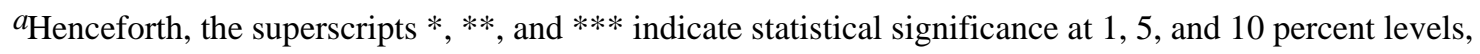
respectively. The null hypothesis is that the series is $I(1)$. I used four lags to augment the $A D F$ unit root regressions. The $A D F$ test critical values are from MacKinnon (1991). 
TABLE III

Cointegrating Regressions of Gross Domestic Investment and National Saving: US, Levels

\begin{tabular}{|c|c|c|c|c|c|c|c|c|c|c|c|}
\hline \multirow[t]{2}{*}{ Period } & \multirow{2}{*}{$\begin{array}{l}\text { Dependent } \\
\text { Variable }\end{array}$} & \multirow[t]{2}{*}{ Constant } & \multirow[t]{2}{*}{ Trend } & \multicolumn{2}{|c|}{ Coefficient on } & \multirow[t]{2}{*}{$\vec{R}^{2}$} & \multirow[t]{2}{*}{$D W$} & \multirow[t]{2}{*}{$A D F^{a}$} & \multicolumn{3}{|c|}{$A D F$ Critical Values } \\
\hline & & & & $I$ & $S$ & & & & $1 \%$ & $5 \%$ & $10 \%$ \\
\hline \multirow{3}{*}{$\begin{array}{l}1897-1989 \\
(n=93)\end{array}$} & $I$ & -5.12 & $0.18^{* *}$ & & $0.96^{*}$ & 0.99 & 1.07 & $-4.20^{* *}$ & -4.50 & -3.88 & -3.57 \\
\hline & & $(-1.10)$ & $(2.10)$ & & $(74.00)$ & & & & & & \\
\hline & $S$ & $\begin{array}{c}1.35 \\
(0.30)\end{array}$ & $\begin{array}{c}-0.09 \\
(-1.00)\end{array}$ & $\begin{array}{c}1.02^{*} \\
(74.00)\end{array}$ & & 0.99 & 1.09 & $-4.26^{* *}$ & -4.50 & -3.88 & -3.57 \\
\hline \multirow{3}{*}{$\begin{array}{l}1829-1989 \\
(n=61)\end{array}$} & $I$ & 0.01 & -0.001 & & $0.97^{*}$ & 0.99 & 1.24 & $-4.87^{*}$ & -4.59 & -3.94 & -3.61 \\
\hline & & $(0.71)$ & $(-0.02)$ & & $(57.00)$ & & & & & & \\
\hline & $S$ & $\begin{array}{l}-18.50^{* * *} \\
(-1.60)\end{array}$ & $\begin{array}{c}0.17 \\
(1.00)\end{array}$ & $\begin{array}{c}1.00^{*} \\
(57.00)\end{array}$ & & 0.99 & 1.29 & $-5.09^{*}$ & -4.59 & -3.94 & -3.61 \\
\hline \multirow{3}{*}{$\begin{array}{l}1897-1945 \\
(n=48)\end{array}$} & $I$ & -0.18 & $0.20^{* *}$ & & $0.86^{*}$ & 0.94 & 1.09 & $-4.46^{*}$ & -4.64 & -3.97 & -3.63 \\
\hline & & $(-0.03)$ & $(2.00)$ & & $(25.10)$ & & & & & & \\
\hline & $S$ & $\begin{array}{c}0.19 \\
(0.03)\end{array}$ & $\begin{array}{c}-0.13 \\
(-1.10)\end{array}$ & $\begin{array}{c}1.07^{*} \\
(25.10)\end{array}$ & & 0.93 & 1.15 & $-4.68 *$ & -4.64 & -3.97 & -3.63 \\
\hline
\end{tabular}

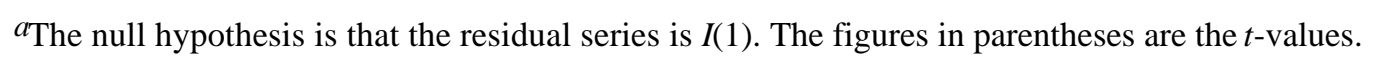


TABLE IV

Cointegrating Regressions of Gross Domestic Investment and National Saving: US, Rates

\begin{tabular}{|c|c|c|c|c|c|c|c|c|c|c|c|}
\hline \multirow[t]{2}{*}{ Period } & \multirow{2}{*}{$\begin{array}{c}\text { Dependent } \\
\text { Variable }\end{array}$} & \multirow[t]{2}{*}{ Constant } & \multirow[t]{2}{*}{ Trend } & \multicolumn{2}{|c|}{ Coefficient on } & \multirow[t]{2}{*}{$\bar{R}^{2}$} & \multirow[t]{2}{*}{$D W$} & \multirow[t]{2}{*}{$A D F^{a}$} & \multicolumn{3}{|c|}{$A D F$ Critical Values } \\
\hline & & & & $I / Y$ & $S / Y$ & & & & $1 \%$ & $5 \%$ & $10 \%$ \\
\hline \multirow{4}{*}{$\begin{array}{l}1897-1989 \\
(n=93)\end{array}$} & $I / Y$ & $0.03^{*}$ & $-0.001^{* * *}$ & & $0.80^{*}$ & 0.87 & 1.08 & $-4.46^{* *}$ & -4.50 & -3.88 & -3.57 \\
\hline & & $(5.40)$ & $(-1.70)$ & & $(25.20)$ & & & & & & \\
\hline & $S / Y$ & $-0.02^{*}$ & $0.001^{* * *}$ & $1.08^{*}$ & & 0.87 & 1.22 & $-4.78^{*}$ & -4.50 & -3.88 & -3.57 \\
\hline & & $(-2.70)$ & $(1.70)$ & $(25.20)$ & & & & & & & \\
\hline \multirow{4}{*}{$\begin{array}{l}1829-1989 \\
(n=61)\end{array}$} & $I / Y$ & $0.02^{*}$ & $-0.001^{*}$ & & $0.95^{*}$ & 0.98 & 1.62 & $-6.22 *$ & -4.59 & -3.94 & -3.61 \\
\hline & & $(6.20)$ & $(-3.20)$ & & $(63.80)$ & & & & & & \\
\hline & $S / Y$ & $-0.02^{*}$ & $0.001^{*}$ & $1.02 *$ & & 0.99 & 1.64 & $-6.29^{*}$ & -4.59 & -3.94 & -3.61 \\
\hline & & $(-6.20)$ & $(3.80)$ & $(63.80)$ & & & & & & & \\
\hline \multirow{4}{*}{$\begin{array}{l}1897-1945 \\
(n=48)\end{array}$} & $I / Y$ & $0.08^{*}$ & $-0.001^{*}$ & & $0.73^{*}$ & 0.88 & 1.24 & $-4.94 *$ & -4.64 & -3.97 & -3.63 \\
\hline & & $(5.40)$ & $(-3.60)$ & & $(16.80)$ & & & & & & \\
\hline & $S / Y$ & $-0.06^{*}$ & $0.001^{* *}$ & $1.15^{*}$ & & 0.87 & 1.29 & $-5.31^{*}$ & -4.64 & -3.97 & -3.63 \\
\hline & & $(-2.70)$ & $(2.20)$ & $(16.80)$ & & & & & & & \\
\hline
\end{tabular}

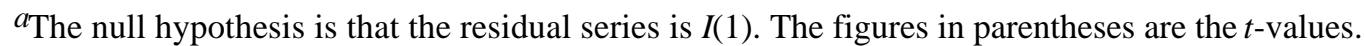




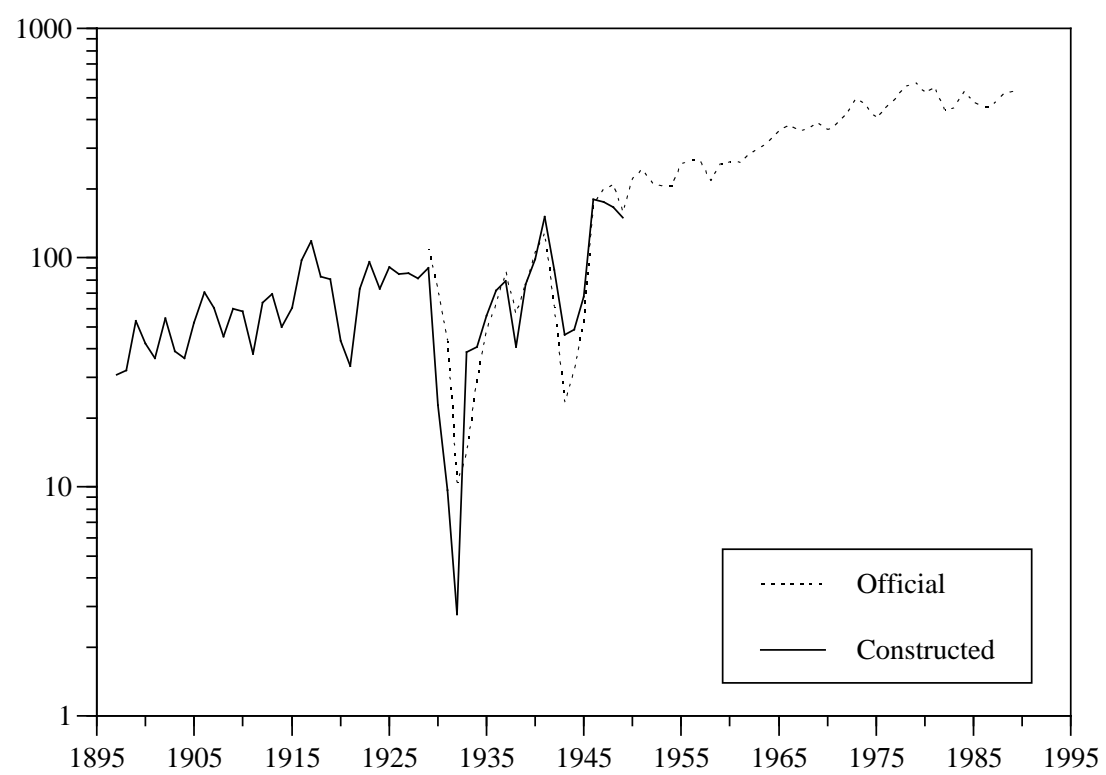

FIG. 1. Constructed and Official Gross Private Domestic Investment: U.S., 1897-1989 (levels on a log scale) 


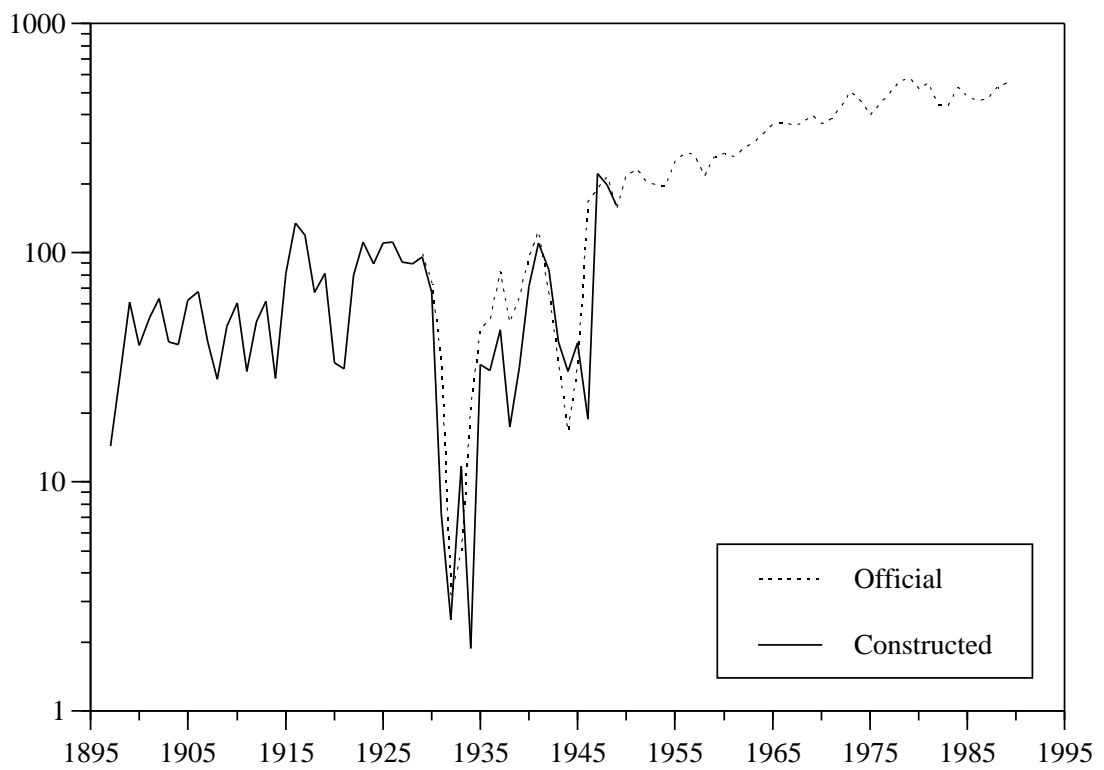

FIG. 2. Constructed and Official Gross National Saving: U.S., 1897-1989 (levels on a log scale) 


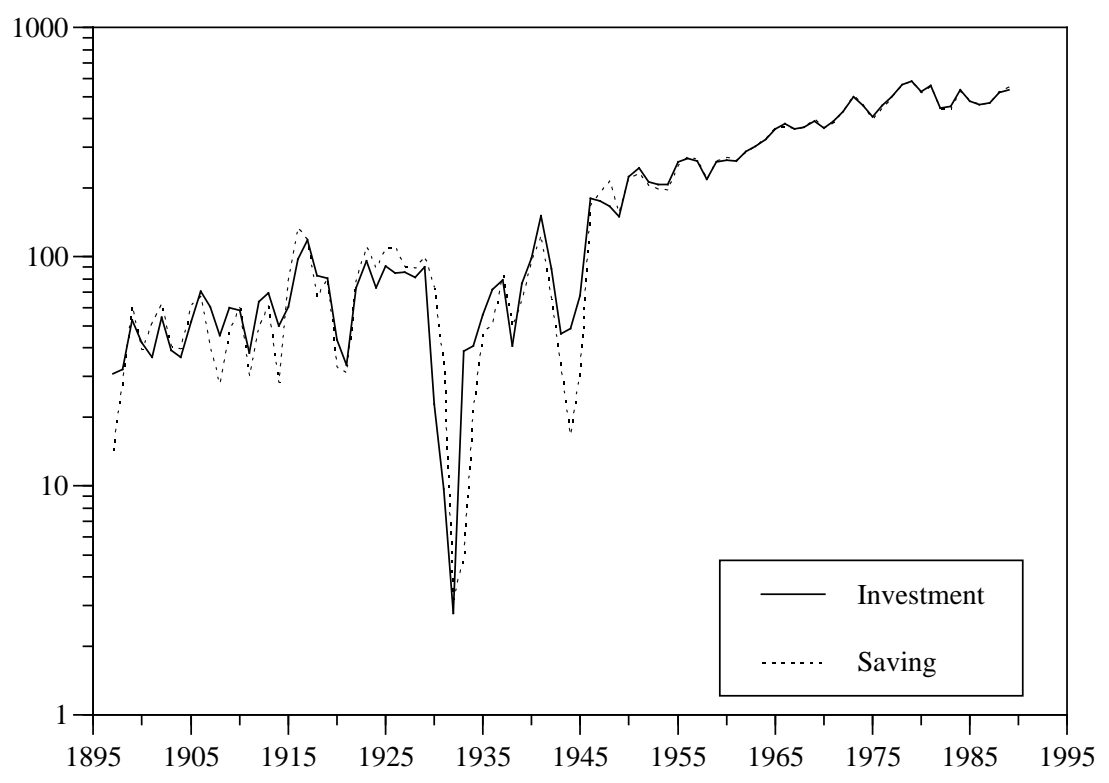

FIG. 3. Gross Private Domestic Investment and Gross National Saving: U.S., 1897-1989 (levels on a $\log$ scale) 


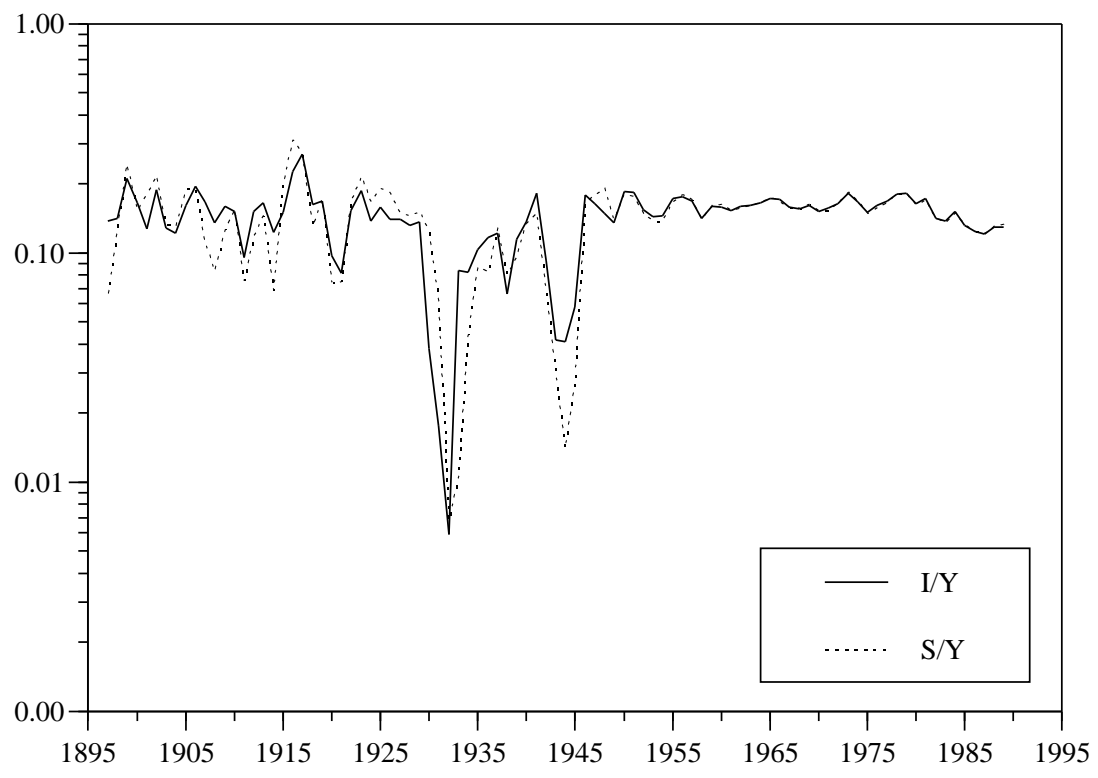

FIG. 4. Rates of Gross Private Domestic Investment and Gross National Saving: U.S., 1897-1989 (rates on a log scale) 


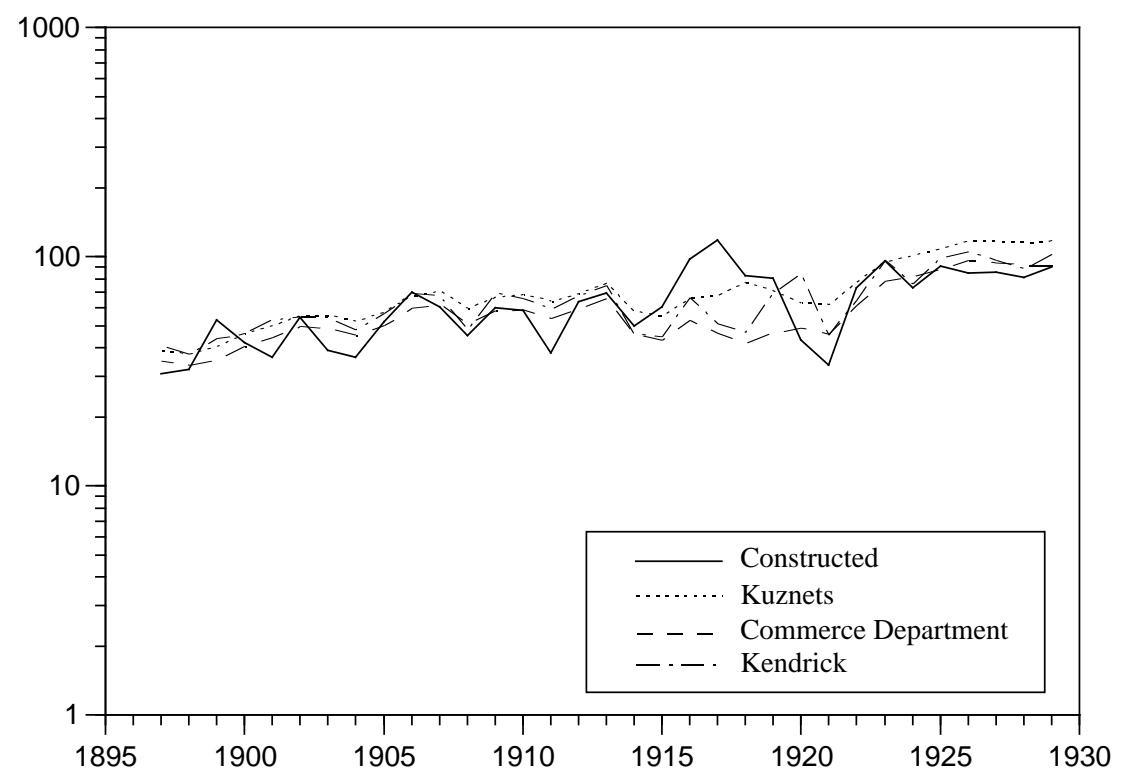

FIG. 5. Alternative Measures of Gross Private Domestic Investment: U.S., 1897-1929 (levels on a log scale) 


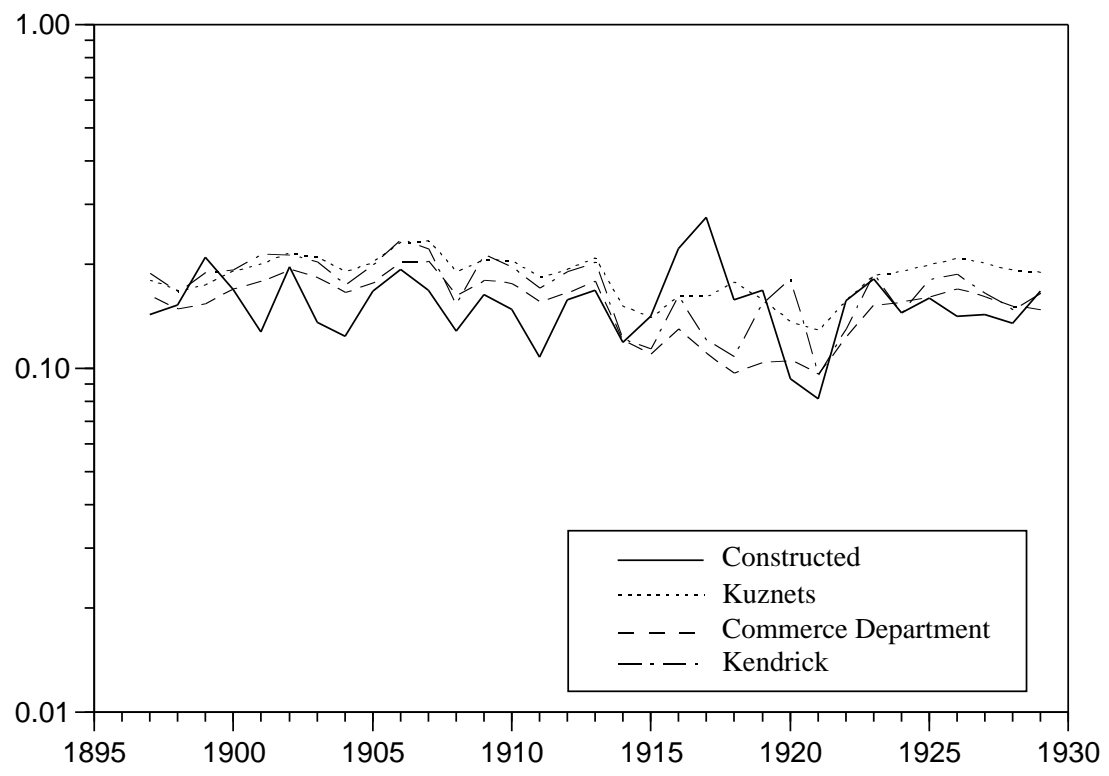

FIG. 6. Alternative Measures of Gross Private Domestic Investment Rate, I/Y: U.S., 1897-1929 (rates on a $\log$ scale) 


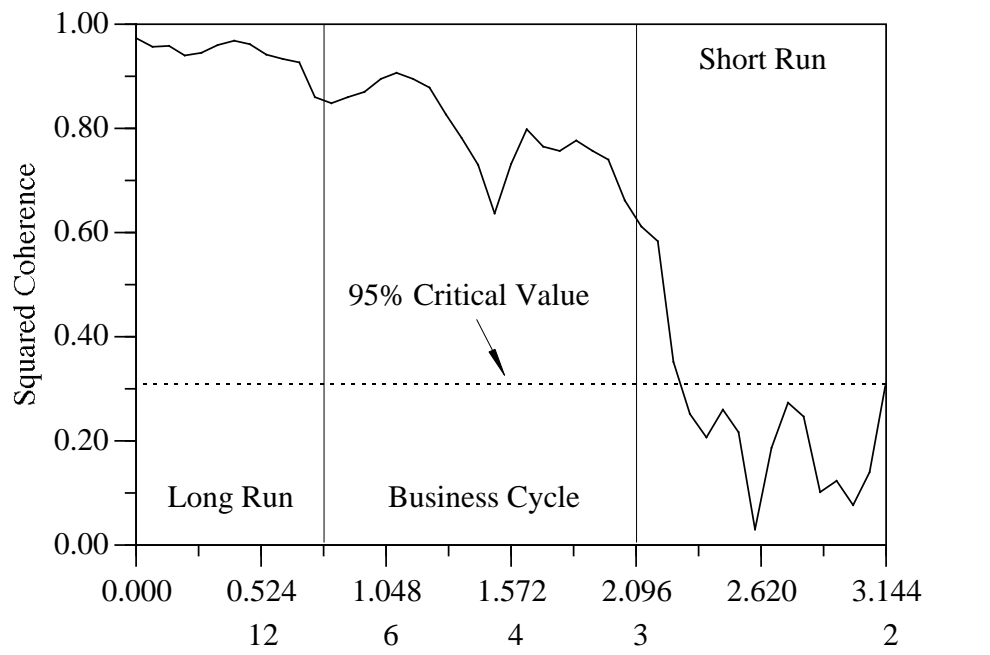

FIG. 7a. Estimated Coherence of National Saving and Domestic Investment: US, Annual Data, 1897-1989 


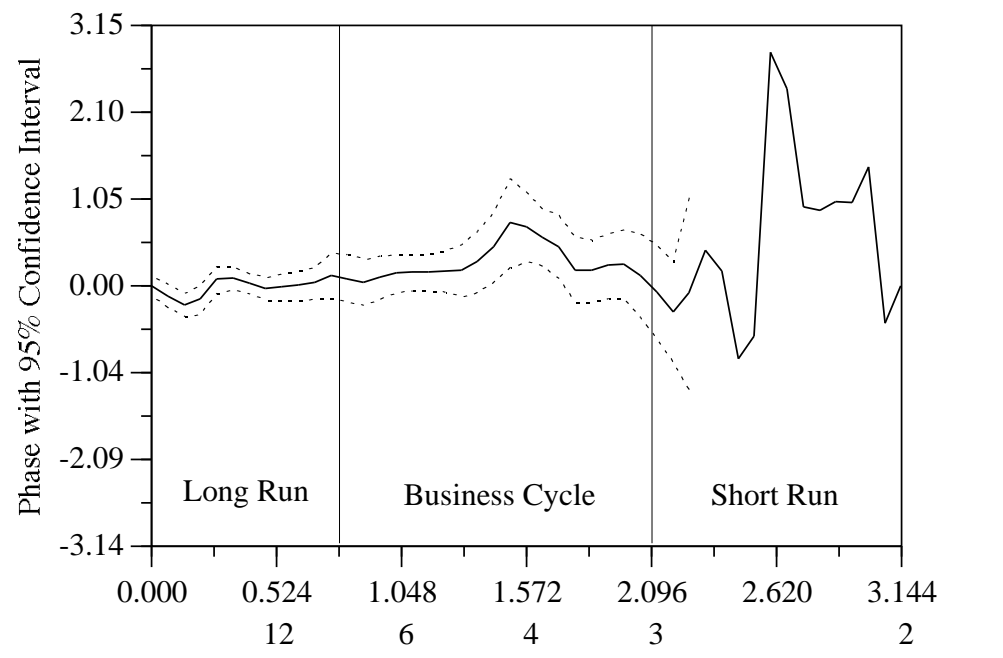

FIG. 7b. Estimated Phase of National Saving and Domestic Investment: US, Annual Data, 1897-1989 


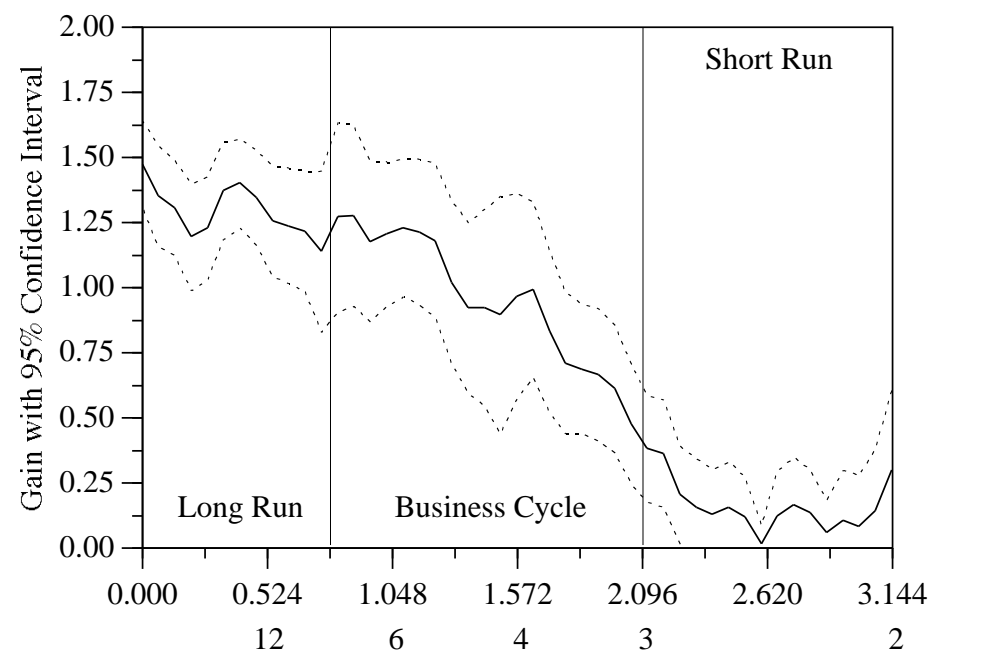

FIG. 7c. Estimated Gain of National Saving and Domestic Investment: US, Annual Data, 1897-1989 


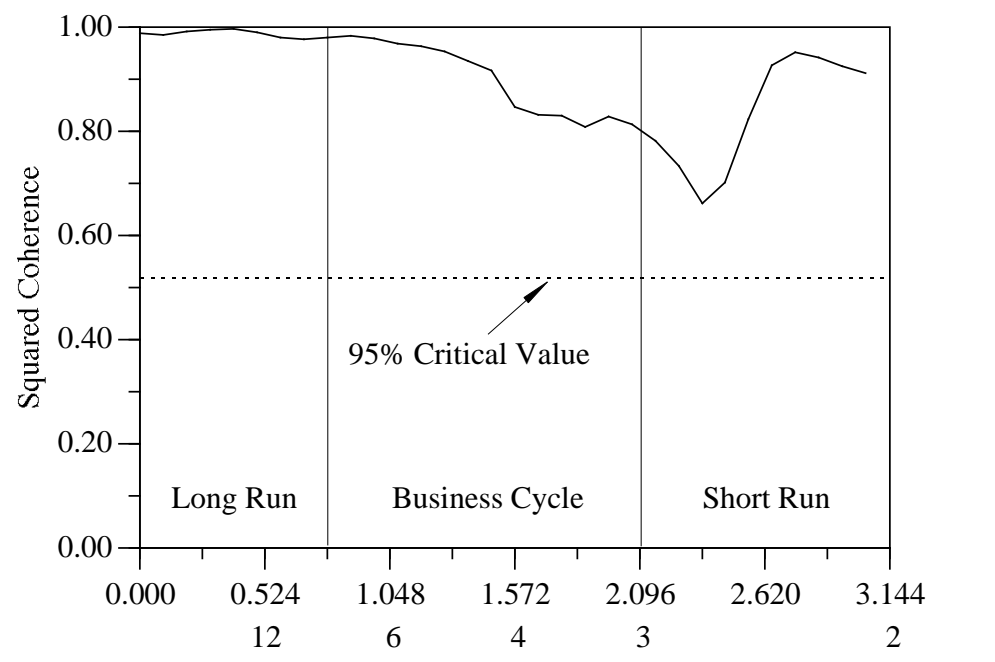

FIG. 8a. Estimated Coherence of National Saving and Domestic Investment: US, Annual Data, 1929-1989 


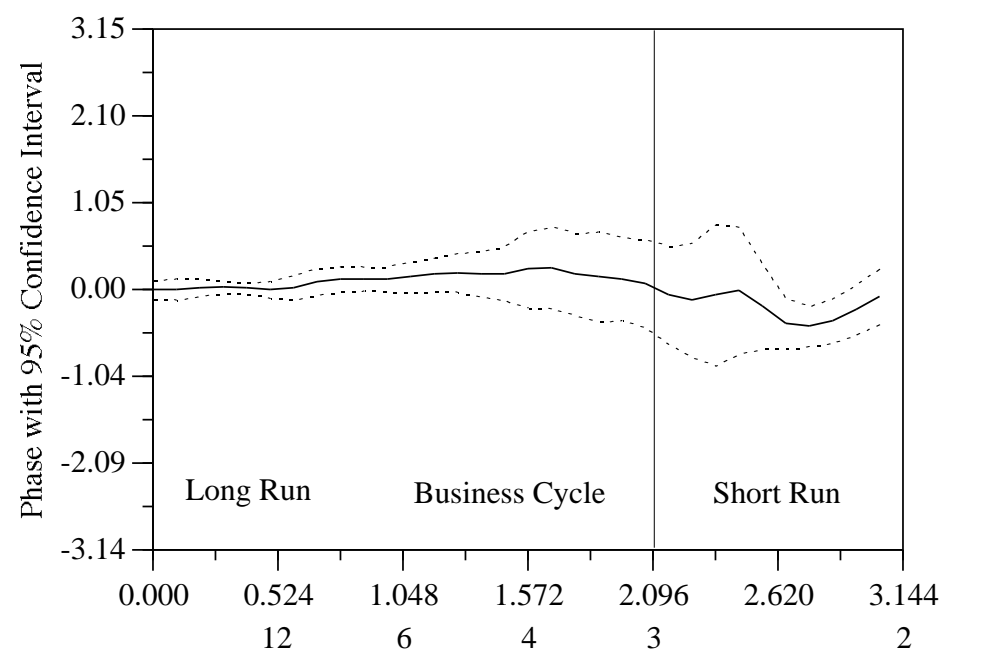

FIG. 8b. Estimated Phase of National Saving and Domestic Investment: US, Annual Data, 1929-1989 


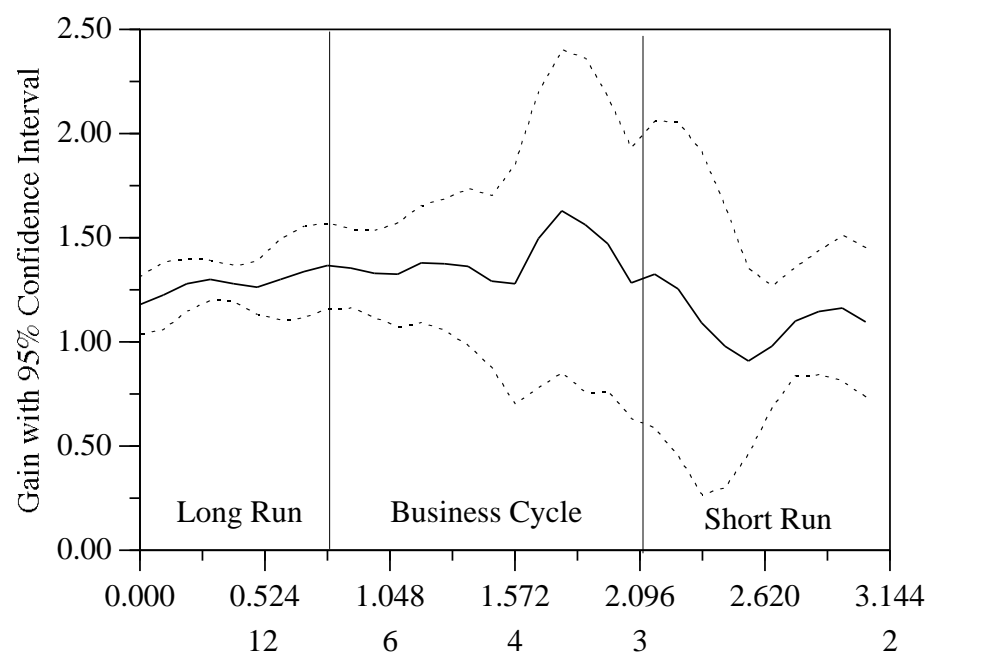

FIG. 8c. Estimated Gain of National Saving and Domestic Investment: US, Annual Data, 1929-1989 


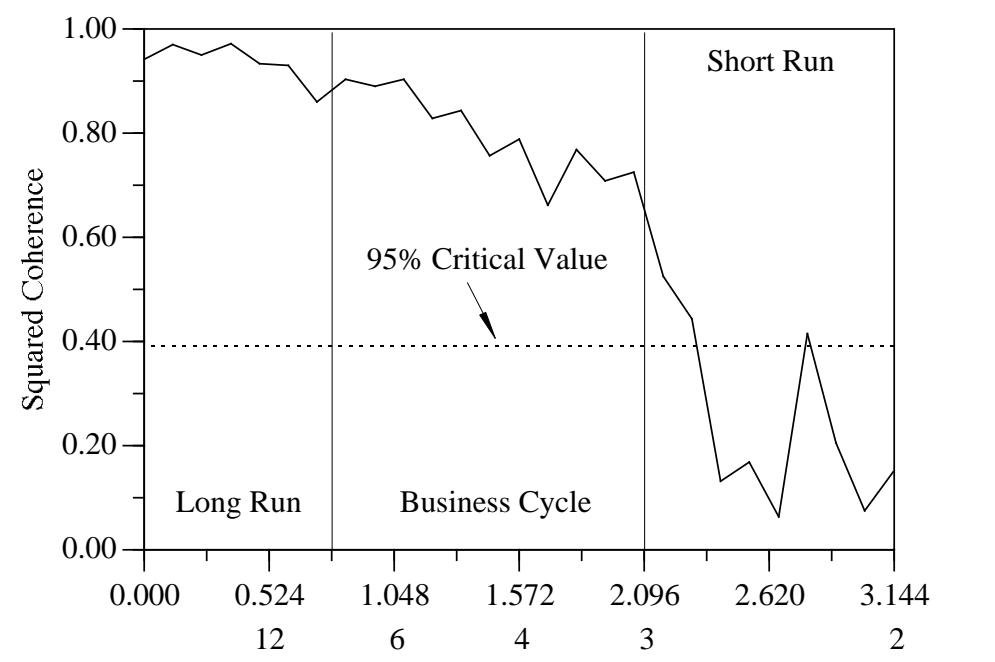

FIG. 9a. Estimated Coherence of National Saving and Domestic Investment: US, Annual Data, 1897-1945 


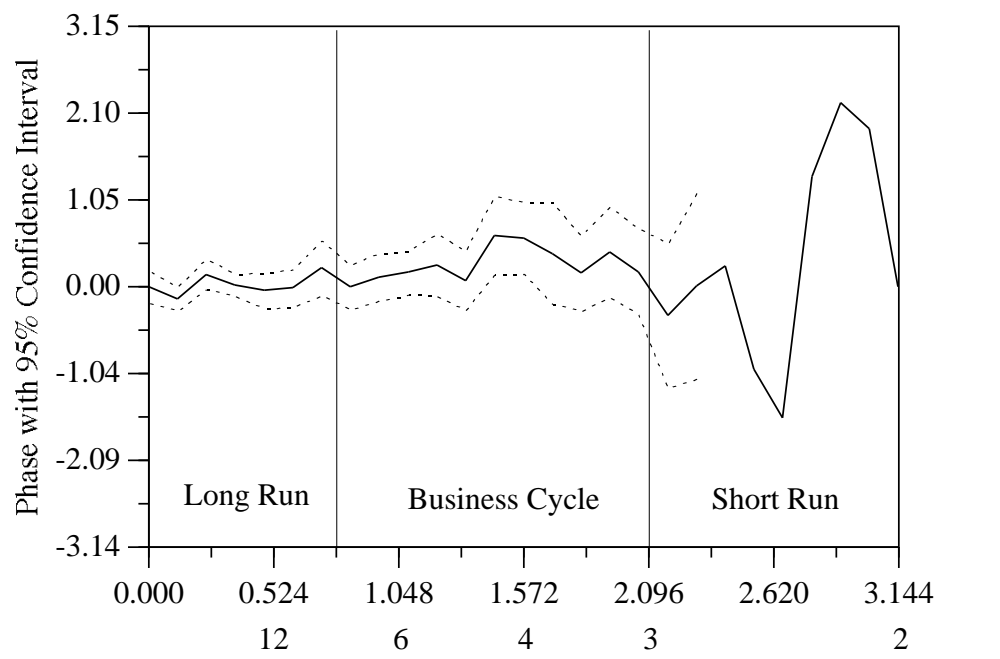

FIG. 9b. Estimated Phase of National Saving and Domestic Investment: US, Annual Data, 1897-1945 


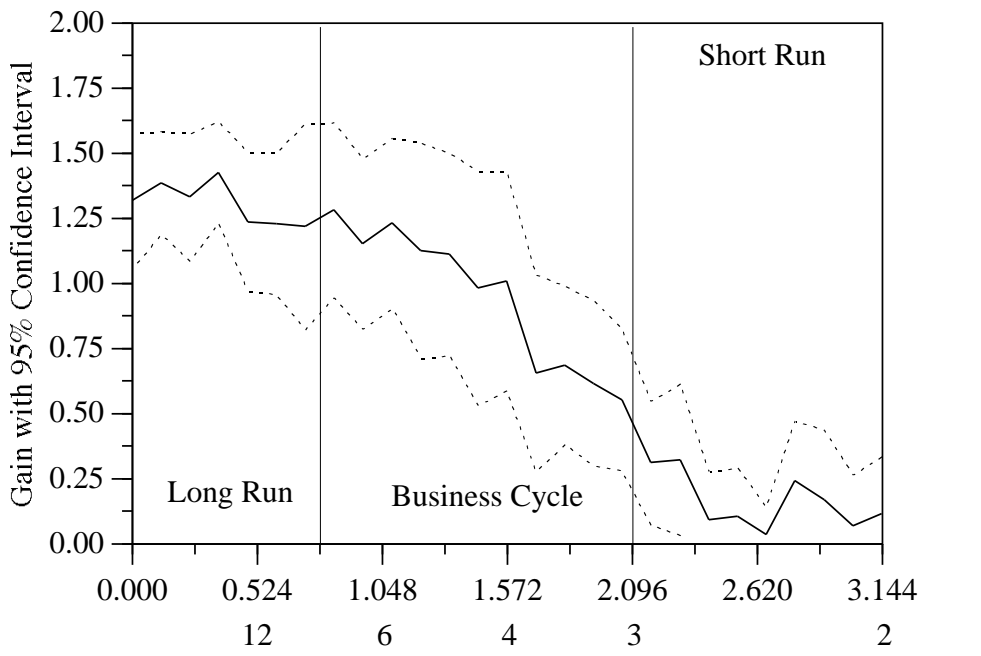

FIG. 9c. Estimated Gain of National Saving and Domestic Investment: US, Annual Data, 1897-1945 


\section{LEGENDS}

FIG. 1. Constructed and Official Gross Private Domestic Investment: U.S., 1897-1989 (levels on a $\log$ scale)

FIG. 2. Constructed and Official Gross National Saving: U.S., 1897-1989 (levels on a log scale)

FIG. 3. Gross Private Domestic Investment and Gross National Saving: U.S., 1897-1989 (levels on a $\log$ scale)

FIG. 4. Rates of Gross Private Domestic Investment and Gross National Saving: U.S., 1897-1989 (rates on a log scale)

FIG. 5. Alternative Measures of Gross Private Domestic Investment: U.S., 1897-1929 (levels on a $\log$ scale)

FIG. 6. Alternative Measures of Gross Private Domestic Investment Rate, I/Y: U.S., 1897-1929 (rates on a log scale)

FIG. 7a. Estimated Coherence of National Saving and Domestic Investment: US, Annual Data, $1897-1989$

FIG. 7b. Estimated Phase of National Saving and Domestic Investment: US, Annual Data, $1897-1989$

FIG. 7c. Estimated Gain of National Saving and Domestic Investment: US, Annual Data, $1897-1989$ 
FIG. 8a. Estimated Coherence of National Saving and Domestic Investment: US, Annual Data, 1929-1989

FIG. 8b. Estimated Phase of National Saving and Domestic Investment: US, Annual Data, 1929-1989

FIG. 8c. Estimated Gain of National Saving and Domestic Investment: US, Annual Data, 1929-1989

FIG. 9a. Estimated Coherence of National Saving and Domestic Investment: US, Annual Data, $1897-1945$

FIG. 9b. Estimated Phase of National Saving and Domestic Investment: US, Annual Data, $1897-1945$

FIG. 9c. Estimated Gain of National Saving and Domestic Investment: US, Annual Data, $1897-1945$ 